\title{
Monofunctionalized Gold Nanoparticles: Fabrication and Applications
}

\author{
E. Henrik Peters ${ }^{a}$ and Marcel Mayor ${ }^{\star a b c}$
}

\begin{abstract}
An overview of various approaches to synthesize gold nanoparticles (AuNPs) bearing one single chemically addressable unit and their diverse fields of application is presented. This comprehensive review not only describes the strategies pursued to obtain monofunctionalized AuNPs, but also reports their behavior as 'massive' molecules in wet chemical protocols and the scope of their applications. The latter reaches from site-specific labels in biomolecules over mechanical barriers in superstructures to building blocks in hybrid nano-architectures. The complementing physical properties of AuNPs combined with precise chemical control of their attachment makes these objects promising building blocks for numerous proof-of-concept experiments and applications.
\end{abstract}

Keywords: Gold Nanoparticle · Labeling · Monofunctional · Plasmonics · Superstructure

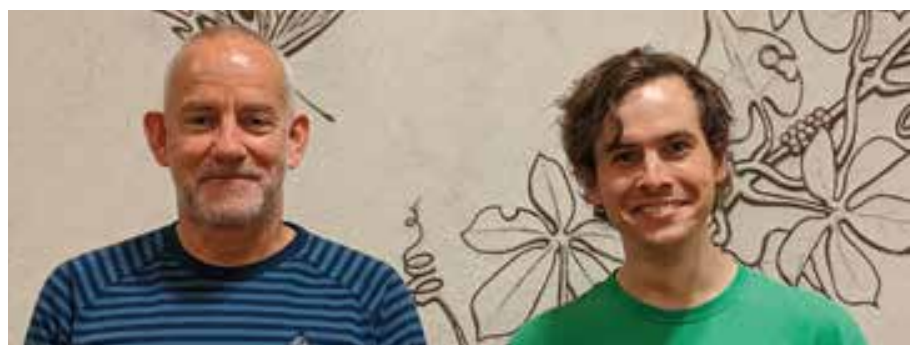

Erich Henrik Peters (right) obtained his MSc in Nanoscience (2015) as well as his PhD in chemistry (2020) at the University of Basel under the supervision of Professor Marcel Mayor on the subject of monofunctionalized gold nanoparticles stabilized by branched thioether-based ligands. He is currently working in the group of Professor Robert Häner at the University of Bern on the supramolecular self-assembly of DNA-inspired oligomers in aqueous media.

Marcel Mayor (left) received his $\mathrm{PhD}$ in 1995 supervised by Professor Rolf Scheffold and Professor Lorenz Walder at the University of Bern. After working with Professor Jean-Marie Lehn at the University Louis Pasteur in Strasbourg and at the Collège de France in Paris, he founded his own research group at the Karlsruhe Institute of Technology in 1998. On defending his habilitation in 2002, he became Professor of Chemistry at the University of Basel in 2004. His current research interests are supramolecular chemistry, molecular electronics, nanoscale architectures, functional materials and hybrid materials.

\section{Introduction}

Due to the reactivity of their surface, nucleating $\mathrm{Au}(0)$ clusters need to be passivated by ligands in order to prevent aggregation. With the recognition of the potential of gold nanoparticles (AuNPs) as functional subunits in nanoscale architectures and molecular devices, the focus of research moved from the bare investigation of their physical properties to their integration in larg- er systems. Consequently, their ligand shell was no longer solely stabilizing the AuNP, but became also of interest as the interface with the chemical environment. Consequently, the decoration of the AuNPs' surface with functional groups enabling their integration as massive 'artificial molecules' by wet chemical protocols moved into the focus of interest. Owing to their non-classical optical ${ }^{[1,2]}$ and physical ${ }^{[3]}$ properties, in the past decades, considerable research efforts were geared towards functional ligand shells for the implementation of AuNPs in sensing, ${ }^{[4,5]}$ catalysis, ${ }^{[6-8]}$ plasmonics, ${ }^{[9-12]}$ labeling, ${ }^{[13-17]}$ molecular electronics, ${ }^{[18-20]}$ and biomedical applications. ${ }^{[16,21,22]}$ For many of these applications, control over the number and spatial arrangement of addressable moieties, i.e. functional groups, exposed on the ligand shell of the AuNPs is of primary interest since it allows the integration of AuNPs with molecular precision.

In this comprehensive review, we provide an overview of various strategies to synthesize monofunctionalized AuNPs as well as the reported proof-of-concept experiments and applications. We differentiate between two strategic approaches to obtain monofunctionalized AuNPs, which are sketched in Fig. 1. In the first part, strategies towards AuNPs stabilized by a single macromolecular ligand exposing a single functional moiety (Type I) are presented. In the second part, the approach consists of AuNPs stabilized by multiple ligands - typically dozens or even hundreds - whereof only one possesses the functionality of interest (Type II). To keep the dimension of this review reasonable, exclusively AuNPs possessing a single functional unit in their ligand shell are considered. Also, we will only occasionally mention AuNPs functionalized with antibodies, as this topic has been extensively reviewed elsewhere. ${ }^{[5,23,24]}$

\section{Single-ligand-coated Gold Nanoparticles (Type I)}

The most straightforward way to synthesize monofunctionalized AuNPs is to design ligands that are large enough to stabilize an entire particle by steric crowding, ${ }^{[25-29]}$ yet the introduction of a single functional unit per ligand demands sophisticated synthetic strategies.

${ }^{*}$ Correspondence: Prof. Dr. M. Mayor, E-mail: marcel.mayor@unibas.ch 


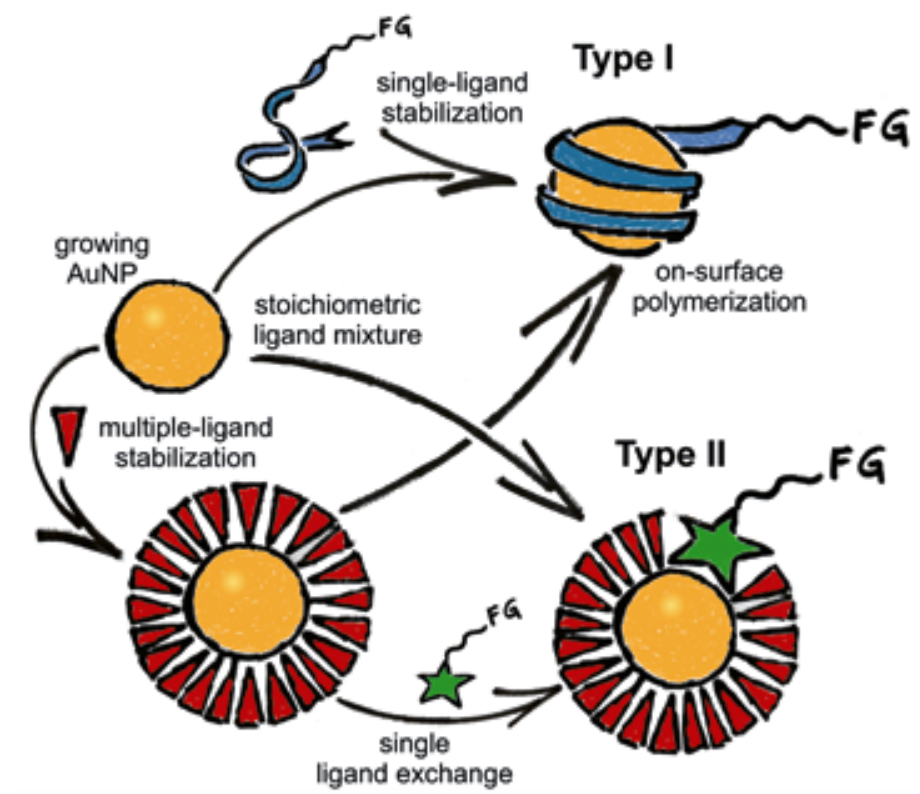

Fig. 1. Illustration of the two strategies geared towards monofunctionalized AuNPs considered in this review. FG = functional group.

\subsection{Oligomers and Polymers}

\subsubsection{Pre-polymerized Ligands}

The first report of AuNPs that were monofunctionalized via a single polymer ligand comprising only one functional unit was published by Wilson. ${ }^{[30]} \mathrm{He}$ reported the use of a dextran-based ligand that was decorated with 15 thiol anchors for the stabilization of AuNPs as well as a single 2,4-dinitrophenyl hapten as a recognition site for antibodies. The latter was attached to the ligand by a short hydrophobic linker in order to pierce its aqueous solvation shell. The $12 \mathrm{~nm}$ AuNPs were prepared by citrate reduction of $\mathrm{HAuCl}_{4}$. Subsequently, the citrate shell was conjugated with various amounts of monofunctionalized dextran polymers. Stability tests against phosphate-buffered saline (PBS)-induced flocculation of the AuNPs revealed that a minimum of four ligands was needed to give AuNPs with satisfactory stability, yielding AuNPs with a minimum of four functional units per particle. Increasing the number of sulfur anchors on the ligand by an order of magnitude gave sufficiently stable AuNPs that were passivated by a single ligand. ${ }^{[31]}$ In this further developed system, the single hapten was replaced by 15 biotins for the detection of streptavidin. Later reports included studies on the functionalization degree dependence for bovine serum albumin detection in lateral flow immunoassays, ${ }^{[32]}$ single-stranded deoxyribonucleic acid (ssDNA) detection ${ }^{[33]}$ and DNA labeling. ${ }^{[34]}$

A variation of this approach was proposed by Yao et al. ${ }^{[35]}$ in which phosphine-stabilized AuNPs were subjected to ligandexchange with a poly-adenine chain long enough to enwrap an entire AuNP, and functionalized with a polynucleotide chain. The latter acted as a recognition motif for the detection of complementary DNA strands or as an anchor for the formation of more complex AuNP superstructures upon DNA hybridization since the number of DNA strands per NP was precisely tuned by the NP size.

An elegant approach to monofunctionalized AuNPs based on tailor-made block co-polymers was reported recently. As sketched in Fig. 2, a linear block co-polymer comprising a block exposing numerous olefins and a terminal azide was obtained by ring-opening metathesis polymerization (ROMP, Fig. 2a). Upon cross-linking with Grubb's catalyst, the olefin-rich block-copolymer formed a cage-like organic NP (ONP) scaffold (Fig. 2b). By oxidizing the olefins of the block co-polymer, a hydroxyl-rich water-soluble ONP was obtained, which still exposed an azide group (Fig. 2c). The latter was engaged in a 'click' protocol to attach a single DNA strand (Fig. 2d). This structure was used to graft $\mathrm{AuCl}_{4}^{-}$to the hydroxyl groups of the organic NP (Fig. 2e). Reduction by addition of ascorbic acid led to AuNP nucleation inside the organic scaffold (Fig. 2f). The preserved function of the single DNA strand was demonstrated by titration with the complementary DNA strand comprising a fluorescence quencher. The monofunctionalization was corroborated by dimer formation with an AuNP functionalized with a complementary DNA strand (Figs. $2 \mathrm{~g}-\mathrm{h}$ ). ${ }^{[36]}$ In continuation of this work, the influence of the polymer size, degree of polymer crosslinking, and monomer-to-polymerization initiator ratio on the organic nanoparticle size were investigated in order to tune the size of the formed metal NPs. ${ }^{[37]}$ Monofunctionalized metal NPs of diameters up to $40 \mathrm{~nm}$ were obtained by this strategy.

\subsubsection{On-Surface Polymerization}

A different approach to the monofunctionalization of AuNPs by polymers was proposed by the research group of Andreas Greiner. ${ }^{[38]}$ In contrast to the previously discussed approach, the polymerization of thiol-derivatives of styrene-based ligand monomers was performed after AuNP synthesis, i.e. on the particle surface. The functional group was introduced by a suitable radical starter initiating the polymer formation. First, AuNPs were synthesized according to the Brust-Schiffrin two-phase synthesis in presence of 4-mercaptostyrene as a small passivating ligand. ${ }^{[39]}$ Subsequently, 4,4'-azobis(4-cyanopentanoic acid) was used as a radical initiator to induce the free-radical polymerization of the ligands' vinyl moieties, giving AuNPs stabilized by a single poly(4-mercaptostyrene) polymer cage. The formed ligand shell had a single carboxyl - the residue of the radical starter - accessible for further chemistry at the terminus of the formed polymer shell (Fig. 3). Monofunctionalization was demonstrated by amide condensation reaction with 1,7-diaminoheptane or with polyallylamine which resulted in either AuNP dimers, or linear AuNP chains respectively. ${ }^{[38]}$ Based on these results, the scope of this monofunctionalization method was enhanced by decorating the radical initiator with a methylcoumarine dye. ${ }^{[40]}$ Free-radical polymerization of the ligand shell gave AuNPs functionalized with a single remote methylcoumarin, making these 'artificial molecules' appealing candidates for labeling applications. In a further study, the particle-coating surface polymer was engaged in a second polymerization reaction. Therefore, the single exposed carboxylic acid was forming an amide bond with 4-aminostyrene which was engaged in the polymerization of methyl methacrylate to give acrylate/AuNP-styrene copolymers. ${ }^{[41]}$ Interestingly, these poly(methyl methacrylate)-grafted polymer ligand shells were acting as 'fishing rods' for size-selective capture of various metal nanoparticles once the ligand shells were liberated from the encapsulated AuNPs templates by $\mathrm{NaCN}$ etching (Fig. 3). ${ }^{[42,43]}$

\subsection{Dendrons, Dendrimers and Branched Oligomers}

Dendrimers as ligands for AuNPs have found significant interest in drug delivery and sensing, ${ }^{[44]}$ catalysis, ${ }^{[45,46]}$ and biomedical applications. ${ }^{[47]}$ The sheer number of end groups in dendrimers, however, poses a major challenge in the monofunctionalization of AuNPs since reliable methods for the modification of a single dendrimer subunit have, to the best of our knowledge, not been reported yet. In first-generation dendrimers with a low number of branches, a single functional group can be statistically introduced. This has been demonstrated by labeling of ssDNA with $\mathrm{Au}_{55}$ clusters that were stabilized by a monofunctionalized benzylic thioether-based dendrimer. ${ }^{[48]}$ Inspired by these studies from Kiedrowski et al., we investigated the potential of benzylic thioether-based oligomers and dendrimers for the stabilization of AuNPs. Already first experiments resulted in AuNPs with nar- 
a)
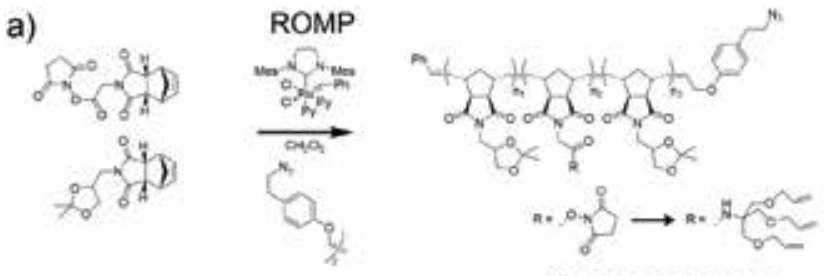

block co-polymer

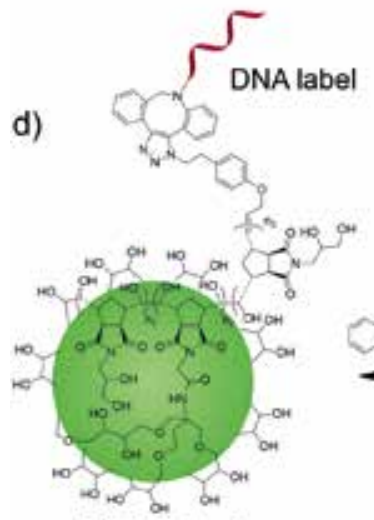

DNA labeled

hydroxyl rich ONP

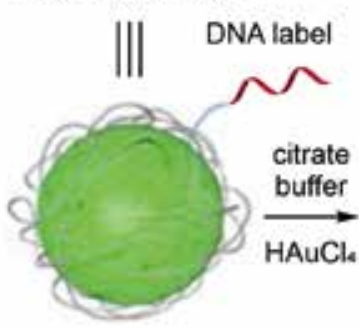

DNA labeled

hydroxyl rich ONP

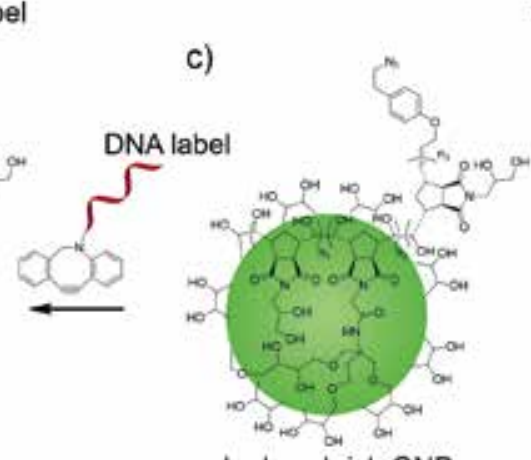

hydroxyl rich ONP e)

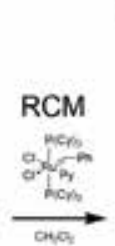

b)

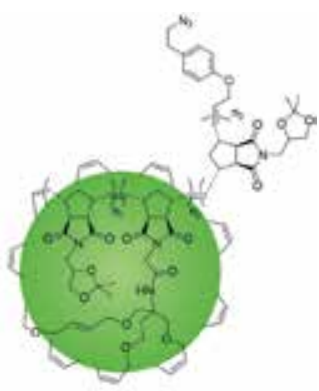

organic nano particle (ONP)

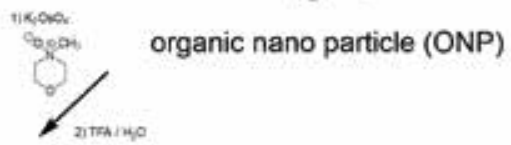

g)

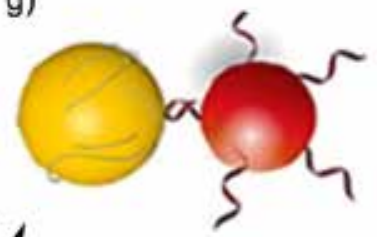

h)

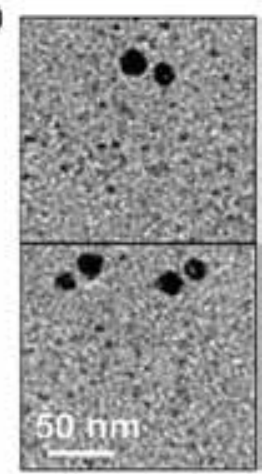

Fig. 2. a) Synthesis of the linear block co-polymer comprising a terminal azide and exposing alkene side-chains. b) Formation of the organic nanoparticle (ONP) by crosslinking the side-chain alkenes via ring closing olefin metathesis (RCM). c) Oxidizing the olefins to 1,2-diols results in a water-soluble hydroxyl-rich ONP exposing a single azide. d) Conjugating the ssDNA to the exposed azide of the ONP. e) Collecting $\mathrm{AuCl}_{4}^{-}$in the ONP. f) Reduction of the $\mathrm{Au}$ salt, yielding the monofunctionalized AuNP. g) Hybridization to parent DNA-functionalized AuNP to form dimers. h) TEM pictures of the dimers. All images adapted with permission from ref. [36]. Copyright (2017) American Chemical Society.

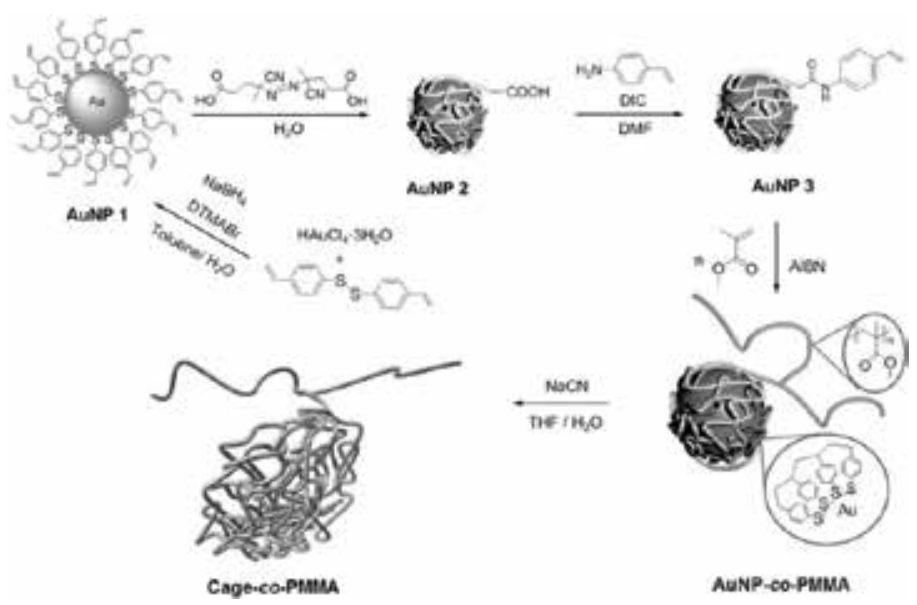

Fig. 3. On-surface polymerization of mercaptostyrene to give monocarboxy AuNP 2. Subsequent amide condensation with aminostyrene and co-polymerization to methyl methacrylate yields acrylate/AuNP-styrene co-polymers. Etching with $\mathrm{NaCN}$ demetalates the polymer cage chains that can be used for size-selective 'fishing' of metal NPs. Reproduced from ref. [43] according to the CC BY-NC-ND 4.0 license. Copyright (2015) John Wiley and Sons.

row dispersity suggesting a discrete number of ligands coating the particle. ${ }^{[27]}$ Decorating the ligands with a single functional group enabled to corroborate the presence of a pair of ligands for meta-benzyl thioether based linear oligomers. ${ }^{[49,50]}$ The AuNP surface covered by the macromolecule was increased by introduc- ing branching units and, indeed, the second-generation dendrimer was not only catching AuNPs of $1.2 \mathrm{~nm}$ diameter during their growth, but also stabilizing the entire particle. ${ }^{[51]}$ Introduction of an exposed alkyne group at the central dendrimer subunit provided dumbbell-type AuNP dimers upon oxidative acetylene coupling ${ }^{[52]}$ and trimeric or tetrameric AuNP architectures upon exposure to copper(I)-catalyzed alkyne-azide cycloaddition (CuAAC) 'click' reaction conditions with central linking units comprising three or four benzylic azides respectively, ${ }^{[53]}$ all corroborating the 1:1 dendrimer:AuNP ratio. Enlarging the steric demand of the coating benzyl thioether ligand by tetraphenylmethane subunits even provided linear ${ }^{[28]}$ and threefold branched ${ }^{[29]}$ oligomers able to coat entire AuNPs. The central tetraphenyl subunit of the latter was ideally suited to expose a single alkyne group enabling again the formation of AuNP dimers or trimers by wet chemical protocols based on oxidative acetylene homocoupling or CuAAC respectively (Fig. 4).[54]

Dendrimers and dendrons were used as host structures for AuNPs mainly as an instrument to profit from the particles' catalytic activity. Parent thioester-based second-generation dendron structures were attached to $\mathrm{SiO}_{2}$ beads as support for AuNPs which were used as a reusable catalyst for the oxidation of alcohols. [55] Dendronized polymers ${ }^{[56]}$ were used for the AuNP-catalyzed reduction of 4-nitrophenol to 4-aminophenol in both aqueous ${ }^{[57]}$ and organic ${ }^{[58]}$ media. An alternate dendron motif based on CuAAC'clicked' triazols ${ }^{[59]}$ was proposed. ${ }^{[60]}$ Upon functionalizing the focal point of the dendron with a disulfide as anchor, it was shown that the resulting AuNPs were indeed stabilized by a single ligand. The parent ligands, functionalized with free acetylene or 


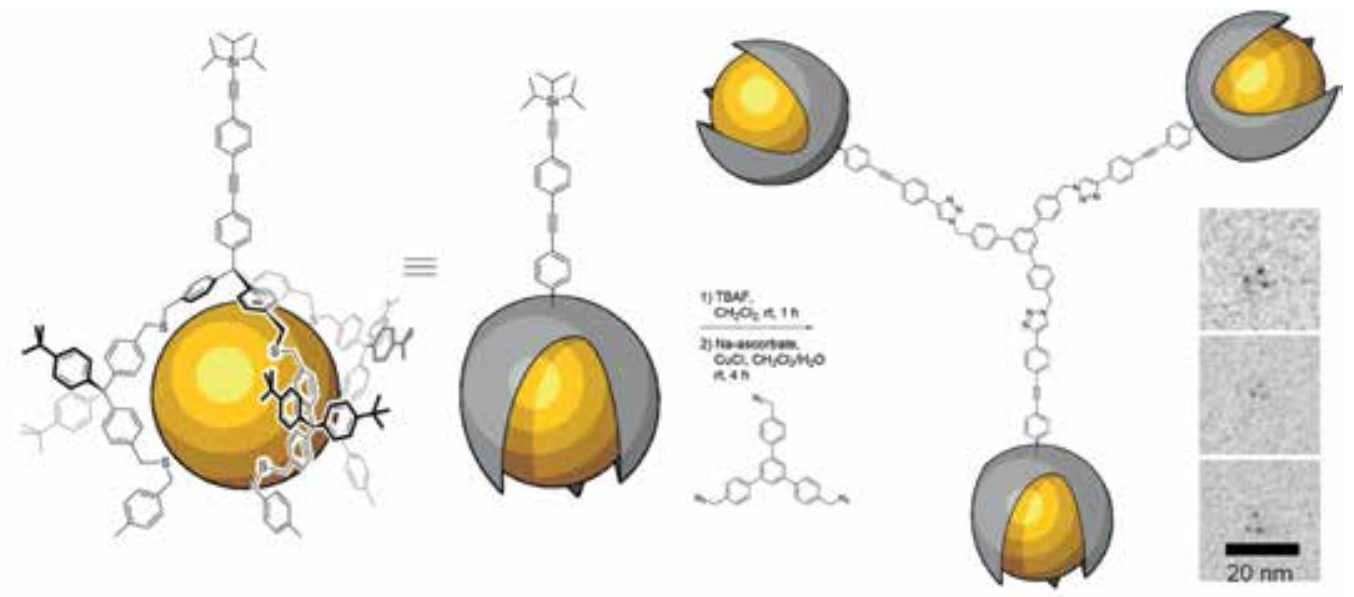

Fig. 4. a) Threefold branched ligand structure coating the AuNP. b) Sketch of its engagement like a huge molecule in a CuAAC 'click' reaction after deprotection of the masked alkyne group. c) TEM micrographs of the obtained AuNP trimers. Reproduced from ref. [54] according to the CC BY 4.0 license. Copyright (2020) John Wiley and Sons.
$N$-hydroxysuccinimide yielded AuNPs stabilized with two dendrons each under otherwise identical reaction conditions, pointing at the importance of the anchoring group for the controlled nucleation of AuNPs to yield a 1:1 ligand-to-particle ratio.

Grafting poly(amido)amine (PAMAM) dendrimers via amide condensation to solid polymer supports ${ }^{[61]}$ has been reported as a means for the facile monofunctionalization of dendrimers: first, the dendrimers were grafted to cellulose nanocrystals, subsequently, the AuNPs were synthesized in presence of these superstructures via sodium borohydride-mediated reduction of chloroauric acid, giving organic superstructures covered by AuNPs. ${ }^{62]}$ These AuNP superclusters were used as catalysts in the reduction of 4-nitrophenol to 4-aminophenol and were recyclable multiple times. A similar approach was used to monitor laccase activity in an electronic monitoring sensor for electron-transfer events upon oxidation of catechin. [63]

\section{Multiple-ligand-coated Gold Nanoparticles (Type II)}

As an alternative to large molecules, AuNPs can be stabilized by dozens or even hundreds of small ligands such as citrate, ${ }^{[64]}$ 4-(dimethylamino)pyridine, ${ }^{[65]}$ tetra- $n$-octylammonium bromide (TOAB), ${ }^{[66]}$ cetyltrimethylammonium bromide (CTAB), ${ }^{67]}$ triphenylphosphine ${ }^{[68,69]}$ or alkyl thiols. ${ }^{[69]}$ In order to obtain monofunctionalized AuNPs from such multiple-ligand-coated AuNPs, two approaches have found widespread application: (1) the synthesis of AuNPs in a stoichiometric ligand mixture containing a carefully chosen ratio of functional and non-functional ligands or (2) exploiting the ligand place-exchange reaction that occurs in presence of a ligand of similar or better affinity to gold than the ligand coating the $\mathrm{NP}^{[70,71]}$ in order to introduce a single functional ligand per NP via statistical ligand-exchange events. In this section, methods documenting one of the two approaches are presented.

\subsection{Stoichiometric Ligand Mixtures}

\subsection{1 $A u_{11}$ Clusters}

The first report of trace evidence of a gold cluster with mixed ligands whereof only one exposed a single chemically addressable functional group was published as early as $1980,{ }^{[72]}$ but it is not before 1984 that parent clusters were isolated. ${ }^{[73,74]}$ In an elaborate protocol based on stoichiometric functionalization, one single amine of tricyanoheptakis [4,4',4"-phosphinidynetris(benzenemethaneamine $)]$ undecagold $\left(\left[\left(\mathrm{P}\left(\mathrm{PhCH}_{2} \mathrm{NH}_{2}\right)_{3}\right)_{7}\right] \mathrm{X}_{3} \mathrm{Au}_{11}\right.$, where $\mathrm{X}=$ halogen) was functionalized with succinimide or phthalimide respectively. ${ }^{[73]}$ Alternatively, $\left[\left(\mathrm{P}\left(\mathrm{PhCH}_{2} \mathrm{NH}_{2}\right)_{3}\right)_{7}\right] \mathrm{X}_{3} \mathrm{Au}_{11}$ was modified with a stoichiometric mixture of phthalic anhydride and acetic anhydride to give a mono-( $N$-phthalyl) undecagold cluster which was further functionalized for tailored needs. ${ }^{[74]}$ These rather laborious methods were optimized by Safer et al. ${ }^{[75,76]}$ who, to synthesize monofunctionalized $\mathrm{Au}_{11}$ clusters, used a stoichiometric mixture of two triphenylphosphine-based ligands, one bearing a single free amine while the other was not functionalized. The monofunctionalized clusters were readily separated in excellent yields from their un- and overfunctionalized parent structures by liquid chromatography. After adequate manipulation of the single free amine per cluster, they were used as site-specific labeling agents for actin, myosin and propomyosin. Alternatively, monofunctionalized $\mathrm{Au}_{11}$ clusters were obtained by stoichiometric ligand place-exchange with suitably functionalized phosphine ligands ${ }^{[72]}$ and subsequent chromatography. ${ }^{[77]}$ These facilitated synthetic approaches allowed reliable labeling of a multitude of biomolecules for TEM detection such as proteins, ${ }^{[13,78]}$ antibodies ${ }^{[79]}$ and RNA, ${ }^{[80-82]}$ whereby, in the latter case, it was shown that the undecagold label did not interfere with the translation process in the ribosome due to its minuscule size ${ }^{[83,84]}$ - in contrast to its $\mathrm{Au}_{55}$ counterpart. ${ }^{[85]}$ Recently, $\mathrm{N}$-heterocyclic carbine-monofunctionalized undecagold was reported to have unprecedented thermal stability and catalytic activity in the electroreduction of $\mathrm{CO}_{2} \cdot{ }^{[86]}$

\subsection{2 $A u_{55}$ Clusters}

The stoichiometric ligand mixture approach was expanded to the monofunctionalization of $\mathrm{Au}_{55}$ Schmid clusters ${ }^{[69]}$ and was commercialized in 1990 together with the $\mathrm{Au}_{11}$ parent clusters under the name 'Nanoprobes' ${ }^{[17,87,88]}$ These commercial gold clusters were used for the synthesis of precisely organized $\mathrm{Au}_{55}$ dimers and trimers by substitution to ssDNA which could hybridize to complementary $\mathrm{Au}_{55}$-labeled strands in pre-defined orientations. ${ }^{[89]}$ Owing to their minute size, they were further used for the labeling of sterically challenging sites on antigens. ${ }^{[85]}$ Their ease of handling was further exploited in the fabrication of organic/inorganic $\mathrm{Au}_{55}$-conjugated double-stranded DNA (dsDNA) and RNA structures. ${ }^{[90]}$ In the same study it was demonstrated that streptavidin covalently labeled with the $\mathrm{Au}_{55}$-DNA conjugates was still performing its natural immunoglobulin $\mathrm{G}(\mathrm{IgG})$ recognition function.

$\mathrm{Au}_{55}$-labeled DNA was further used to study the DNA de- and re-hybridization as a function of magnetic field-induced temperature increase: a 38-nucleotide DNA hairpin with self-complementary ends over 7 bases was labeled with $\mathrm{Au}_{55}$ cluster (Fig. 5a). ${ }^{[91,92]}$ The de- and re-hybridization of the 7-base sequence upon radiation with a radio-frequency magnetic field was monitored by measuring the optical absorbance at $260 \mathrm{~nm}$ which reflects the hybridization state of the loop (Fig. 5b). The temperature calibration of the experiment was obtained by profiting from an immobilized DNA strand which was conjugated with a complementary DNA strand decorated with $\mathrm{a} \mathrm{Au}_{55}$ cluster and a fluorophore at opposed ends (Fig. 5c). De-hybridization was triggered by either heat or the radio-frequency magnetic field with the extent of dehybridization monitored by the fluorophore concentration in the 


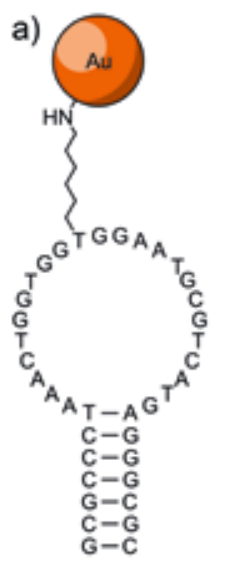

b)

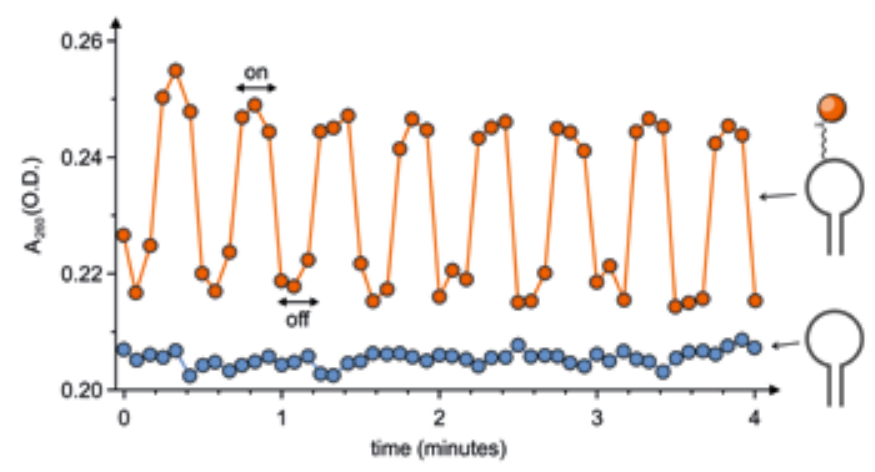

c)

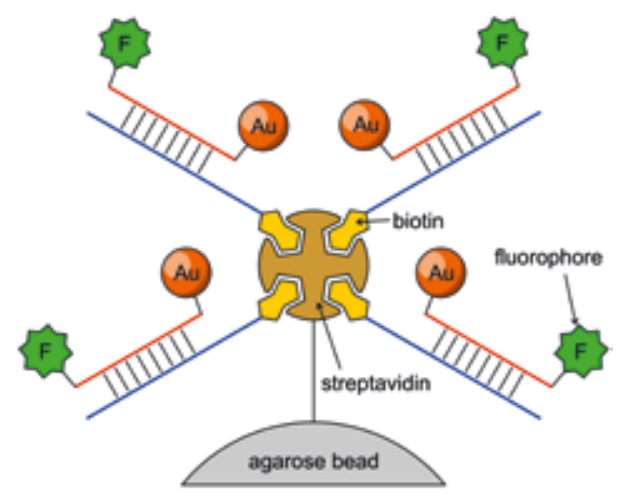

Fig. 5. a) DNA hairpin loop labeled with $\mathrm{Au}_{55}$. b) Change in absorbance at $260 \mathrm{~nm}$ upon switching of the radio-frequency magnetic field, reflecting the de- and re-hybridization of the DNA duplex. c) Set-up of paired DNA strands used for temperature calibration in the experiment. Sketched from ref. [91] and ref [92].

supernatant. Equal fluorophore concentrations in the supernatant point at comparable effective temperatures experienced by the paired DNA strands in the set-up.

Willner and co-workers covalently attached $\mathrm{Au}_{55}$ to a DNA intercalator and profited from a dsDNA as a template to obtain wire-like arrays of AuNPs. ${ }^{[93]}$ In the same article, the exposed amino groups of polylysine were functionalized with mono- $N$ hydroxysuccinimido- $\mathrm{Au}_{55}$ from 'Nanoprobes' as alternative approach to AuNP wires. ${ }^{[53]}$ The same group profited from $\mathrm{Au}_{55}$ as functional unit in a biology-inspired electrochemical experiment monitoring the apo-glucose oxidase activity in real-time. ${ }^{\text {[94] }} \mathrm{By}$ wet chemical control, a single $\mathrm{Au}_{55}$ was coupled to flavin adenine dinucleotide (FAD). The AuNPs were further place-exchanged to a gold wire electrode via thiolated bridge molecules. Upon oxidizing glucose, an electron was transferred from FAD to the attached AuNP, giving a detectable signal on the electrode. The natural enzyme relying on electron transfer from FAD to oxygen was outperformed by a factor of seven. ${ }^{[94]}$

Pons et al. investigated the fluorescence quenching of $\mathrm{CdSe}-$ $\mathrm{ZnS}$ quantum dots (QDs) by AuNPs by controlling the spacing between both particles with a beta-sheet-forming repeating sequence. ${ }^{[95]}$ By variation of the length of the beta-sheet rod, the distance-dependence of the quenching was studied and, indeed, quenching occurred even beyond separation distances of $200 \AA$, suggesting nonradiative energy dissipation and dipole-to-metal nanoparticle energy transfer to be a better model for quantum dot photoluminescence quenching than Förster resonance energy transfer.

\subsubsection{Ligand-exchange with Stoichiometric Ligand Mixtures}

In order to stabilize larger gold colloids with stoichiometric ligand mixtures, Brust's group proposed to exchange the entire ligand shell of $13 \mathrm{~nm}$ and $40 \mathrm{~nm}$ citrate-stabilized AuNPs with a carefully tuned mixture comprising an unfunctionalized, cysteine-containing pentapeptide and its DNA-functionalized parent peptide, allowing the controlled supramolecular assembly of AuNP nanoarchitectures via DNA hybridization. ${ }^{[96]}$ The scope of the method was enlarged by replacing the DNA-conjugated functional peptide by a biotin-labeled pentadecapeptide containing a $\mathrm{His}_{6}$-tag which can chelate to transition metals. ${ }^{[97]}$ In the latter case, isolation of the monofunctionalized AuNPs was achieved by metal ion affinity chromatography. In order to prove the versatility of the approach, different functional peptide chains were used, enabling the AuNPs to bind to proteins. ${ }^{[98]}$ The approach was later generalized by using an alkyl-poly(ethyleneglycol) ligand as the non-functionalized ligand. ${ }^{[99]}$ Peptide-monofunctionalized AuNPs were used to label various proteins, ${ }^{[99-102]}$ target lipid rafts of cell membranes, ${ }^{[103]}$ and to study the effect of NP surface functionalization density on the supramolecular assembly behavior of bis(sulfosuccinimideyl)suberate (BS3) with peptide chains on the AuNP surface.[104] Interestingly, the experimental data suggest that thus-synthesized AuNP labels do not interfere with the function of their target protein. ${ }^{[100]}$

Using a comparable statistical ligand-exchange protocol, Jun et al. reported a study monitoring the cleavage of peptide-linked AuNP superstructures by caspase-3: AuNPs monofunctionalized with a biotinylated peptide bearing the caspase- 3 cleavage site were attached to NeutrAvidin-coated AuNPs attached to a solid support. Monitoring the plasmon resonance wavelength as well as the scattering intensity allowed the recording of single caspase- 3 cleaving events by a blue-shift of the plasmon band and a drop in intensity for each cleaving (Fig. 6). ${ }^{[105]}$ In the same report, this method was implemented into in vivo systems in order to monitor caspase-3 activity in apoptosis processes.

Similar studies used mixtures of unfunctionalized hydrophobic ligands and linear oligo(phenylene-ethynylene)(OPE) dithiols to create AuNP dimers or star-shaped OPE trithiols to create AuNP trimers respectively. ${ }^{[106]}$ While the existence of both AuNP dimers and trimers was corroborated by transmission electron microscopy (TEM), the AuNP superstructures were not isolated. Mechanically interlinked structures with an AuNP as intrinsic subunit of the catenated macrocycle were also reported.[107] Both phenantroline ligands of a copper complex were terminally decorated with short ethyleneglycol chains exposing a terminal thiol, allowing to close the macrocycle by immobilizing both ends of each ligand to an AuNP. The concentration ratios between copper complex and AuNP were optimized for catenated dimer formation.

\subsection{Single Ligand-exchange Events}

For AuNPs stabilized by multiple ligands beyond the $1.4 \mathrm{~nm}$ $\mathrm{Au}_{55}$ cluster, often more elaborate procedures have to be used in order to obtain reliable monofunctionalization. Single ligand place-exchange events were reported in liquid phase as well as on solid support. In the first case, between various assembly and purification strategies has to be differentiated, namely exploiting the negative charge of e.g. (but not limited to) DNA in gel electrophoresis, using single polymerase chain reaction (PCR) cycles, place-exchange at the liquid-liquid interface of biphasic mixtures, 
a)

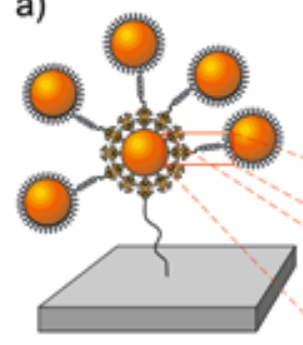

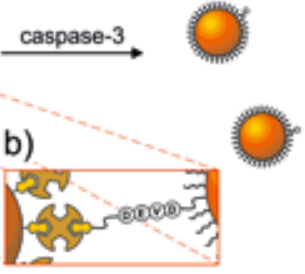

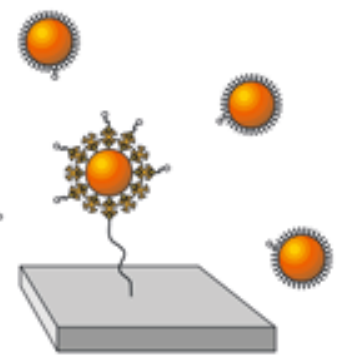

c)

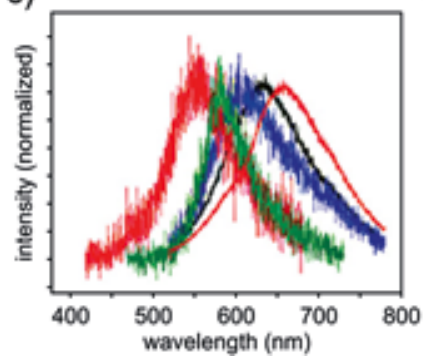

d)

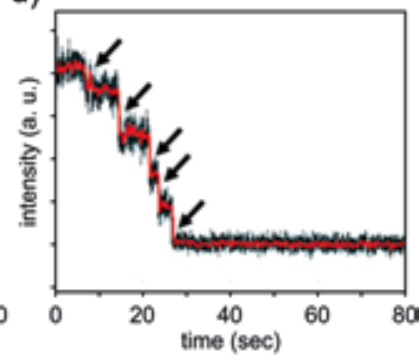

Fig. 6. a) Monofunctionalized AuNPs attached to stationary AuNP via a peptide chain bearing the caspase recognition motif (DEVD) and caspasemediated degrading of the superstructure. b) Sketch of the avidin-biotin immobilization chemistry and the caspase-sensitive DEVD peptide sequence (Asp-Glu-Val-Asp). c) Gradual plasmon band blue-shift and decreasing of signal-to-noise ratio with increasing number of cleaving events. The solid red line is the absorption of the intact structure, the increasing fuzziness of the curves reflects the decrease of signal-to-noise ratio when AuNPs are cleaved off the central AuNP. d) Scattering intensity as a function of time, showing a distinct decrease for each cleaving event. Reproduced from ref. [105].

or separation by centrifugation. Solid-support place-exchange reactions require pre-functionalized stationary chromatography phases that will be discussed in the second part of this chapter.

\subsubsection{Liquid-phase Place-exchange \\ 3.2.1.1 DNA-monofunctionalized Gold Nanoparticles by Electrophoresis}

In order to circumvent the challenges faced by embedding a single functional group into the ligand shell, Alivisatos and coworkers exploited the negative charge of DNA and its influence on separation behavior: they place-exchanged phosphine-, ${ }^{[108-110]}$ tannic acid-, ${ }^{[111]}$ or citrate-stabilized[110,111] AuNPs with stoichiometric amounts of thiolated ssDNA and separated the obtained products by number of attached DNA strands via electrophoresis, ${ }^{[108,110,111]}$ or anion-exchange HPLC. ${ }^{[109]}$ The ability for reliable control over the degree of functionalization allowed, via DNA strand hybridization, the fabrication of precisely organized AuNP dimers and trimers, ${ }^{[108,112,113]}$ structurally switchable di-, ${ }^{[114]}$ triand tetramers, ${ }^{[115]}$ extendable hairpin DNA-AuNP tetramers, ${ }^{[116]}$ chains, ${ }^{[117]}$ chiral and achiral AuNP tetrahedrons, ${ }^{[118]}$ AuNP transport machineries ${ }^{[119]}$ as well as highly organized 2-dimensional AuNP arrays, ${ }^{[120,121]}$ or DNA origami slabs ${ }^{[122]}$ on surfaces (Fig. 7).

This method further allowed to probe the NP-NP distance-dependence of the surface plasmon resonance of AuNP dimers. ${ }^{[123,124]}$ Both studies found that a significant redshift can be observed if the AuNPs are moved closer together. Temperaturedependent UV-vis monitoring of the plasmon absorption signal in dsDNA-linked AuNP dimers showed a drastic redshift of the plasmon band upon heating. ${ }^{[125]}$ Further, the size-dependence of the individual AuNPs in dsDNA-linked heterodimer structures was investigated. ${ }^{[124]}$ Förster resonance energy transfer amplification for fluorescent donor-acceptor pairs located at the center between AuNP dimers with well-defined interparticle distance was reported. ${ }^{[126]}$ Trimer assemblies with interparticle gaps in the subnanometer regime were shown to act as plasmon nanolenses. [127]

The method was used to fabricate rotaxanes consisting of a partially double-stranded DNA axle with AuNPs acting as stoppers on each end. The macrocycle consisted of a circular ssDNA which was hybridized with a single-stranded domain of the axle as well as a third ssDNA-functionalized AuNP or a fluorophore (Fig. 8a). ${ }^{[128]}$ The thus-functionalized macrocycle was able to shuttle between the stoppers upon addition of suitable DNA fuel strands (Fig. 8b). With these structures, geometry-dependent plasmon resonance behavior of AuNP assemblies as well as distance-dependent fluorescence quenching and amplifying was investigated, being in close agreement with theoretically predicted surface plasmon-enhanced luminescence in noble metal nanoparticles. ${ }^{[129,130]}$ In a closely related work, both plasmonics and fluorescence quenching and amplifying behavior of precisely organized AuNP assemblies were further investigated with the help of complex catenated AuNP-macrocyclic DNA structures which were able to change morphology by exchange of DNA fuel strands. ${ }^{[131]}$ Further, mono-DNA AuNPs served as probes for the measurement of rotary and shuttling motions of DNA origami rotaxanes. ${ }^{[132]}$

The distance-dependent plasmon properties of AuNP dimers were exploited to fabricate a 'plasmon ruler' where AuNPs functionalized with a single biotinylated ssDNA were anchored to surface-immobilized, streptavidin-coated AuNPs. With higher $\mathrm{NaCl}$ concentration in the buffer, the DNA strand curled up, bringing the AuNPs closer together and thus resulting in a plasmon redshift, while, with lower $\mathrm{NaCl}$ concentration, stretching of the DNA strand resulted in a plasmon blueshift. ${ }^{[133]}$ This type of 'plasmon ruler' was used to monitor endonuclease activity with high time-resolution as single $\mathrm{Au}-\mathrm{DNA}-\mathrm{Au}$ cutting events resulted in a drastic drop of scattering intensity upon release of AuNPs into the buffer solution. [134]

DNA hybridization was exploited for the attachment of sin-

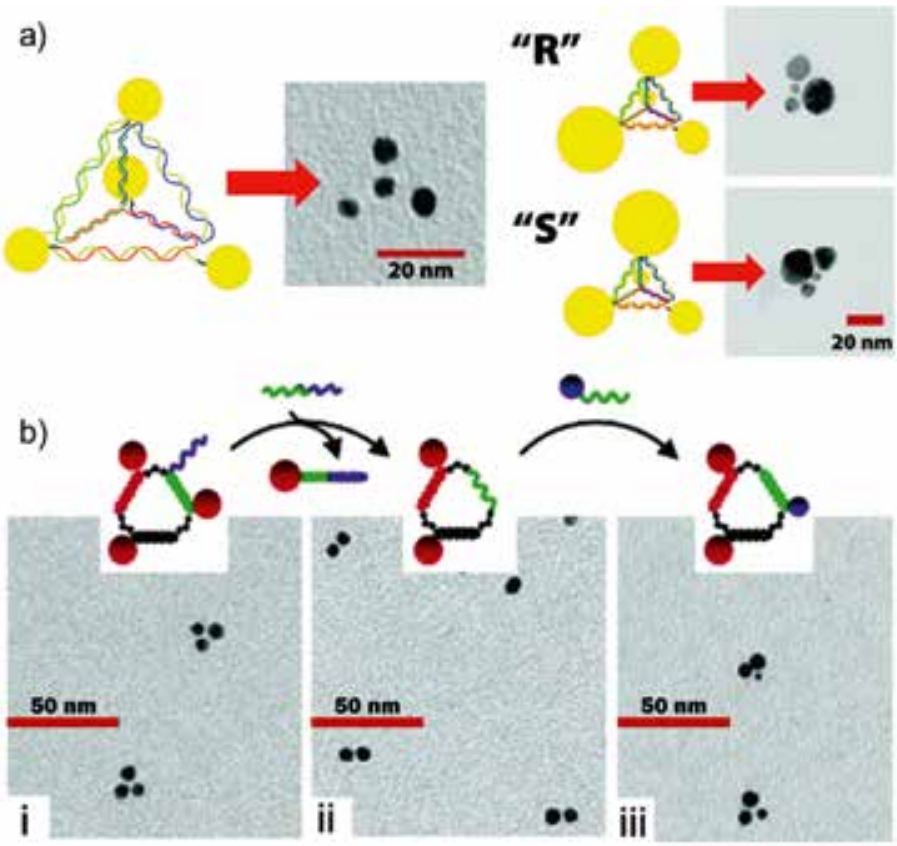

Fig. 7. a) Examples of superstructure assemblies from DNA-monofunctionalized AuNPs. a) Chiral and achiral AuNP tetrahedrons. Reprinted with permission from ref. [118]. Copyright (2009) American Chemical Society. b) Controlled NP exchange in a trimer structure by a 'write/erase' procedure. Adapted with permission from ref. [115]. Copyright (2007) American Chemical Society. 
a)

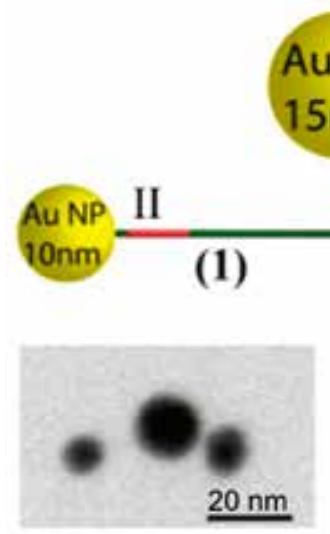

b)

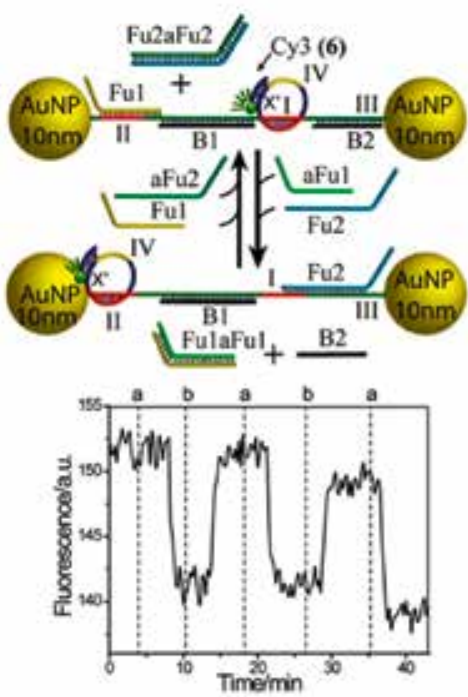

Fig. 8. a) AuNP-DNA-rotaxane with a third AuNP attached to the macrocycle. Domains I and II (red): ssDNA part of the axle. Domain III (green): dsDNA part of the axle. Domain IV (yellow): recognition site for the SSDNA-functionalized AuNP. The AuNP can shuttle between domains I and II. b) SSDNA macrocycle labeled with fluorescence marker for fluorescence quenching experiments Adapted with permission from ref. [128]. Copyright (2017) American Chemical Society. gle inactive thiolated hairpin DNA strands to AuNPs: an asymmetric DNA hairpin bearing a thiol at its sterically crowded hybridized end while the overhang is not functionalized cannot bind to a gold surface. In order to attach the inactive hairpin, phosphine-stabilized AuNPs were subjected to single placeexchange reaction with thiolated helper DNA strands. Those acted as competitive strands, allowing the loop to open upon hybridization and to expose the unreachable thiol. With this approach, the attached DNA lost its loop structure, but left an overhang for further functionalization of the AuNPs (Fig. 9a). Alternatively, a helper DNA with a hybridizable sequence and an overhang was first hybridized with the overhang of the loop DNA, thus freeing the inactive thiol while leaving the loop intact and finally, enabling the attaching to the AuNP surface (Fig. 9b). Using this procedure left the loop able to hybridize with further ssDNA as well as a hybridizable overhang from the helper DNA for individually accessible functionalizations of the AuNPs. These two methods allowed the controlled fabrication of AuNP superstructures such as di-, tri- and tetramers upon hybridization with either the intact loop, the helper DNA overhang or the stretched loop overhang (Fig. 9c). ${ }^{[135]}$ In continuation of this work, controlled strand displacement events on the helper strands were used to create AuNP-based 'AND', 'OR' and 'YES' logic circuit functions.[136]

\subsubsection{Alternate Functional Groups Using Electrophoresis for Purification}

Several groups have shown that the versatility of electrophoresis as a means of isolating AuNPs bearing a single functional group is not limited to DNA functionalization. A similar procedure based on electrophoretic separation was implemented for the monofunctionalization of AuNPs by monoamino poly(ethyleneglycol) chains. ${ }^{[137]}$ This modified method allowed to trace the accumulation of AuNPs in living animals from both intravenous injection and intratracheal instillation. ${ }^{[138]}$ In another approach, AuNPs were stabilized by 11-mercaptoundecanoic acid. Ligand-exchange with stoichiometric amounts of 1,6-hexanedithiol gave interconnected AuNP structures which could be separated by gel electrophoresis owing to the anionic charge on the structure's surface. With this method, precisely ordered di- and trimers were isolated. ${ }^{[139]}$ The potential of electrophoresis for AuNPs was demonstrated with the self-assembly of protein cage-AuNP hybrid nanoarchitectures obtained by surface engineering. ${ }^{[140]}$ The AuNP exposed a single $\mathrm{Ni}^{2+}$ complex which was introduced by place-exchanging citrate with a thiolated molecule exposing a nitrilotriacetic acid subunit coordinating $\mathrm{Ni}^{2+}$ ions. This Ni-complex at the AuNP surface interacts with the polyhistidine tag exposed by a protein cage. Depending on the concentrations of the surface-engineered nanoobjects, a variety of discrete AuNP-protein hybrid architectures were obtained (Fig. 10).

Recently, $p$-mercaptobenzoic acid-coated $\mathrm{Au}_{102}$ and $\mathrm{Au}_{250}$ clusters were subjected to stoichiometric place-exchange reaction with biphenyl-4,4'-dithol. After separation of the dimers from the unreacted monomers and oligomers, it was found that the dimers were formed by disulfide formation of the exposed thiol. These well-defined structures of moderate size made them excellent model compounds for connecting $a b$ initio theoretical studies and experimental quantum plasmonics. These dimers not a)

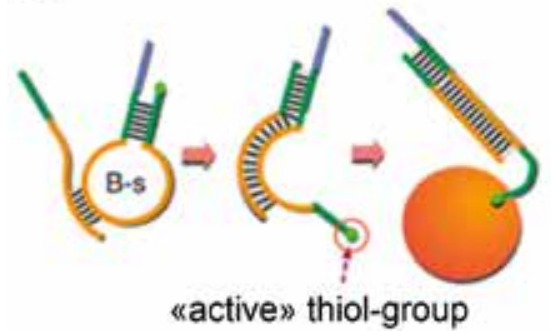

b)

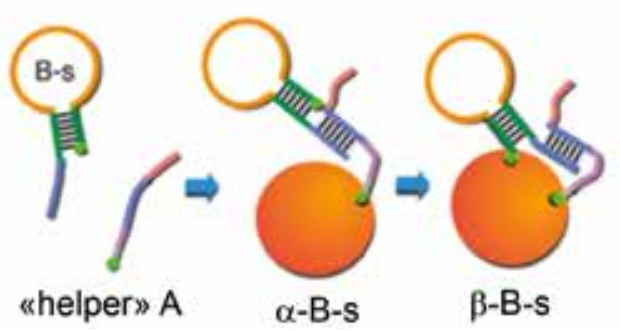

c)

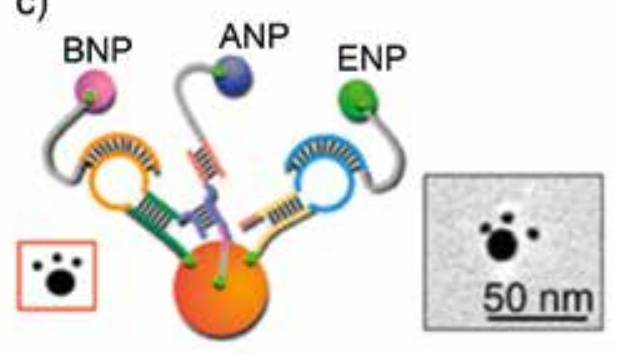

Fig. 9. a) Opening the hairpin DNA loop via hybridization allows access to the sterically crowded thiol, leaving the loop overhang exposed; b) Helper DNA hybridizes to DNA loop overhang, exposing the thiol. The helper DNA overhang is accessible for hybridization; c) AuNP tetramer structure demonstrating the presence of the corresponding DNA architectures at the AuNP surface. Small, ssDNA-monofunctionalized AuNPs hybridize to the specific target functional units on the large AuNP. Adapted with permission from ref. [135]. Copyright (2013) American Chemical Society. 


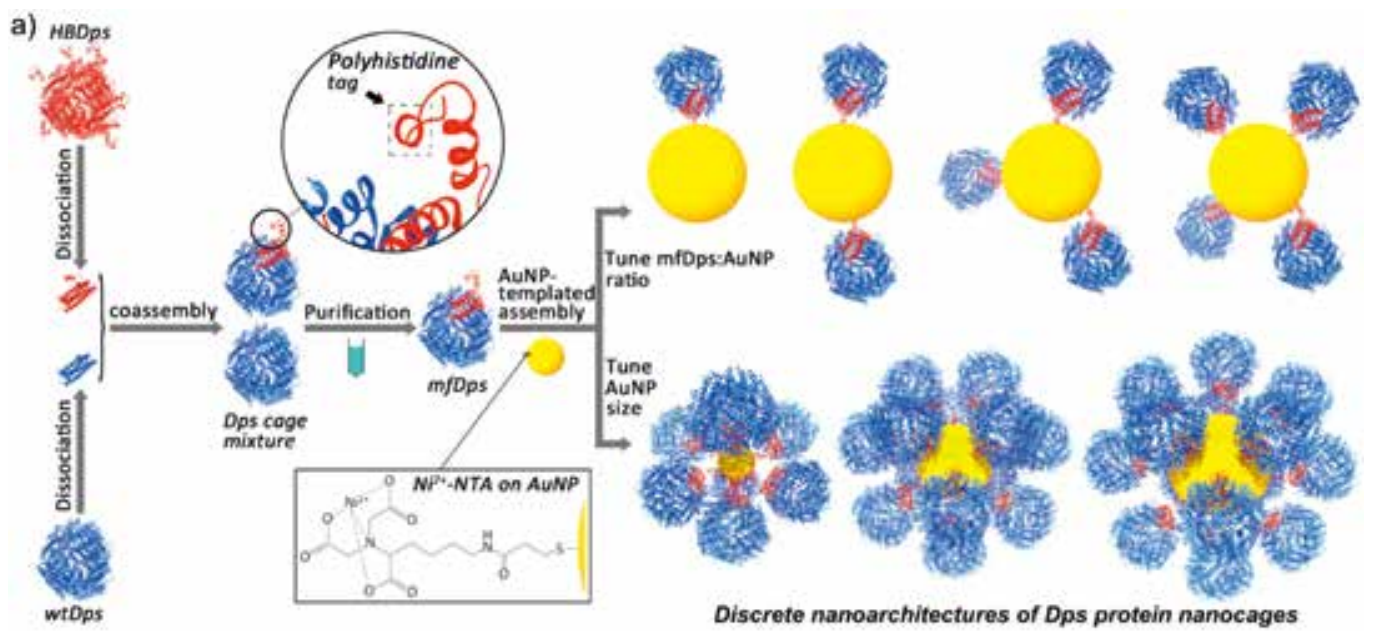

Fig. 10. a) Sketch of the conceptual approach assembling discrete hybrid nanoarchitectures controlled by the protein-cage/AuNP ratio. b) TEM images of discrete hybrid nano objects isolated by electrophoresis. Adapted with permission from ref. [140]. Copyright (2015) American Chemical Society.

b)

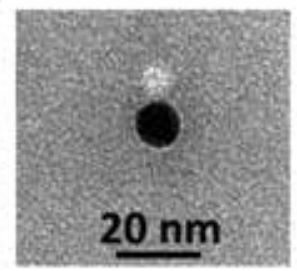

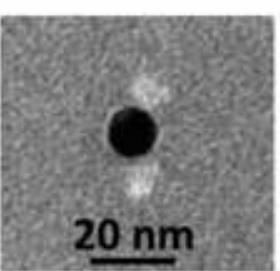

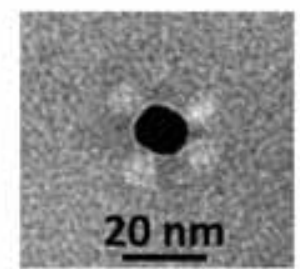

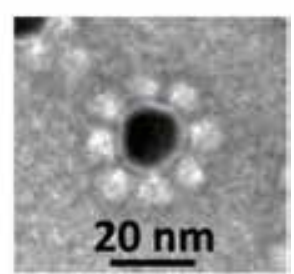

only showed large red-shift in their plasmon resonance, but also a second plasmon resonance mode most likely stemming from tunneling charge transfer phenomena. ${ }^{[141]}$ In a later study, a series of alternate dithiol linkers was investigated in order to gain insight into the influence of the linker structure on the AuNP superstructure polymerization behavior. ${ }^{[142]}$ This approach was further used as a proof-of-principle method for the imaging of individual disulfide bonds via electron energy-loss spectroscopy in scanning transmission electron microscopy experiments on AuNP dimers. ${ }^{[143]}$

\subsubsection{Polymerase Chain Reaction for the Monofunctionalization of Gold Nanoparticles}

In order to functionalize AuNPs with single DNA strands, PCR was used on AuNPs coated with DNA primers. ${ }^{[144]}$ It was demonstrated that, for single PCR cycles, monofunctionalization is achieved while multiple cycles give AuNPs functionalized with two or more DNA strands, making this method a powerful candidate for automated AuNP superstructure assembly. The scope of this approach was shown by DNA pairing-driven assembly of chiral core-satellite and dendriform structures ${ }^{[145]}$ as well as twosized AuNP heterodimers ${ }^{[146]}$ and chiral pyramids that show optical activity in circular dichroism spectroscopy measurements. ${ }^{[144,147]}$ Further, alternating heterochains of different-sized AuNPs fabricated by PCR have been shown to exhibit a direct dependence of structure chain length with plasmon absorption intensity and strength of surface-enhanced Raman scattering.[148]

\subsubsection{Two-phase Mixtures}

An alternative approach to functionalize AuNPs with a single DNA strand was proposed by Jhaveri et al. They used methyl triethylenegylcol thiol for the stabilization of AuNPs. After placeexchanging the ligand with sub-stoichiometric amounts of thiolated ssDNA in a two-phase mixture (water and ethanol/dichloromethane), unreacted AuNPs preferred migrating to the organic phase while DNA-functionalized AuNPs preferably stayed in the aqueous phase. Salting out the free DNA was found to be a facile purification method. Proof of purity of monofunctionalized AuNPs was shown by gel electrophoresis. ${ }^{[149]}$
In another study, citrate-stabilized AuNPs in aqueous phase were brought into contact with an organic phase containing stoichiometric amounts of 11-mercaptoundecyl methacrylate which place-exchanged with the ligands at the liquid-liquid interface. In presence of styrene and a radical initiator, styrene-acrylatecopolymer chains carrying AuNPs were synthesized. Since the backbone of the polymer was hydrophobic and the AuNPs had a hydrophilic ligand shell, AuNP chains were formed in organic media while the structures aggregated to micelles in water. ${ }^{[150]}$ This method proved to be an attractive pathway for the formation of AuNP vesicles and core-shell-corona structures ${ }^{[151]}$ as well as vesicles containing $\mathrm{Fe}_{3} \mathrm{O}_{4}$ NPs embedded in the wall. ${ }^{[152]}$ In later reports, this strategy was used to fabricate cross-linked one- and multi-component hollow capsules which acted as nanocontainers for organic solvents in aqueous media via radical polymerization $^{[153]}$ or anthracene photodimerization. ${ }^{[154]}$

In an inverted variant of this protocol, AuNPs stabilized by a hydrophobic ligand shell were dispersed in toluene and placeexchanged with a stoichiometric aqueous solution of tiopronin, giving AuNPs carrying a single carboxylic acid function as demonstrated by synthesis of AuNP dimers via amide condensation with ethylenediamine for the assembly of plasmonic superstructures. ${ }^{[155]}$

\subsubsection{Centrifugation}

Since place-exchange reactions are not limited to intrinsically charged ligands, the obvious limitations of gel electrophoresis regarding the nature of the ligand shell and mere sample size have pushed researchers to find alternate means for the isolation of discrete AuNP structures. In order to isolate precise AuNP assemblies by degree of functionalization, centrifugation has been used, yielding AuNP dimers connected by a single dithiol for the measurement of conductance through a single molecule ${ }^{[156]}$ or to exploit the Raman scattering properties of Au NP dimers in cancer detection. ${ }^{[157]}$

A more elaborate protocol for the assembly of AuNP coresatellite structures was proposed by the group of Chad Mirkin: to ssDNA-functionalized $\mathrm{SiO}_{2} \mathrm{NPs}, 27-$ mer DNA strands were hybridized on 7 base-pairs to give a 20-base ssDNA overhang 
to which complementary ssDNA-functionalized AuNPs can hybridize over 12 base-pairs. An excess of AuNPs guarantees full passivation of the $\mathrm{SiO}_{2}$-bound DNA. In order to passivate the free DNA strands attached to the AuNPs, complementary strands were incubated with the superstructures. Because of the difference in hybridization lengths on the respective part of the bridging DNA between the $\mathrm{Au}$ and $\mathrm{SiO}_{2}$ NPs (7 base-pairs vs 12 base-pairs), the DNA was selectively de-hybridized via careful temperature tuning to give AuNPs with one single 15-base overhang. These structures were used to form planet-satellite-type structures with larger, ssDNA-saturated AuNPs, which can be effectively purified by centrifugation (Fig. 11). ${ }^{[158]}$

More recently, isolation by centrifugation was used to stopper a thiol-derivatized cucurbit[7]uril ferrocene pseudorotaxane with AuNPs to study the electrochemical electron transfer kinetics of the ferrocene in the rotaxane axle. ${ }^{[159]}$

\subsubsection{Solid-phase Place-exchange}

In solid-phase place-exchange strategies, the extent of the ligand-exchange reaction shall be limited to the small interaction surface between the AuNP and the solid substrate. The first protocol profiting from such an approach for the monofunctionalization of AuNPs was reported by Worden et al. in 2004[160] and optimized soon thereafter.[161] In their approach, Worden et al. loaded $n$-butanethiolate-stabilized AuNPs onto a polystyrene Wang resin which was functionalized by 6-mercaptohexanoic acid via an ester bond on the carboxyl moiety. In contact with the resin's free thiols, a single place-exchange reaction occurred on the AuNPs due to the limited interaction surface between NP and solid support. In a subsequent step, the ester bond was cleaved upon addition of trifluoroacteic acid (TFA), thus releasing the AuNPs exposing a single carboxyl group. Proof of concept was brought by amide condensation reaction with 1,7-diaminoheptane to give AuNP dimers. ${ }^{[160,161]}$ This procedure opened the doors to the formation of larger, highly ordered AuNP structures such as trimers, ${ }^{[162]}$ necklace-type macrocycles via amide condensation to polylysine and subsequent cyclization to AuNP necklace structures ${ }^{[163]}$ and amide condensation to oligo-AuNP PAMAM dendrimers. ${ }^{[164]}$ The necklace structures served as a template for the investigation of the optical, plasmonic and electromagnetic coupling behavior of AuNPs located in close proximity to each other. The studies favored a dipole-dipole interaction model for the de- scription of optical AuNP-AuNP interaction ${ }^{[165]}$ and suggested inefficient electron surface scattering as the limiting phenomena in the optical experiment.[166]

Variations of the Worden procedure were reported using boronic ester-functionalized polymer resins which had a free thiolate that place-exchanged with non-functional ligands on AuNPs. The boronic ester was cleaved by transesterification, giving AuNP functionalized with a single diol ligand.[167] A further publication reported AuNPs functionalized with carboxylic acids that underwent amide condensation on Fmoc-protected lysine-decorated polystyrene and poly(ethylene glycol)acrylamide beads. Passivation of the free carboxyl groups on the AuNP and subsequent cleavage of the ester gave mono-carboxyl-terminated AuNPs as proven by dimerization reaction with ethylenediamine. ${ }^{[168]}$ Another closely similar approach used magnetic beads covered with crown ether acting as hosts for ammonium guests comprising a disulfide anchor, forming a pseudorotaxane with a dithiol axle. Place-exchange reaction with non-functional ligands on AuNPs and subsequent deprotonation of the ammonium caused pseudorotaxane de-threading, releasing monofunctional AuNPs. These readily formed pseudorotaxane-based supramolecular assemblies with suitable guests. ${ }^{[169]}$ In a later publication, the single amine moiety of the pseudorotaxane axle was further functionalized with maleimide which was then 'clicked' to thiolated single-stranded bacterial DNA sequences. This system showed promising potential in sensing and medical applications via hybridization to target DNA strands. ${ }^{[170]}$ Alternatively, silica beads or a Rink resin were functionalized with free amines that bound to the carboxylate of 11-mercaptoundecanoic acid ionically. Upon ligand place-exchange with unfunctionalized AuNPs and subsequent treatment with acetic acid, monocarboxyl AuNPs were generated as proven by dimer formation via amide condensation with ethylenediamine. ${ }^{[171,172]}$ The usage of cellulose as the solid support was reported in a further variation of the method in order to create mono- and divalent AuNPs for the formation of AuNP chains and rings. [173]

An interesting solid-phase mono-functionalization approach was reported by Dewi et al., providing AuNPs exposing a terpyridine subunit as coordination site. Silica nanoparticles functionalized with a terminal carboxylic acid were subjected to amide condensation with an amine-functionalized terpyridine derivate first. Upon complexation with an iron ion and another equivalent of the amine-functionalized terpyridine derivate, the silicon
Fig. 11. a) Strategy for the formation of planet-satellite AuNP structures. ssDNA-coated silica bead (1) is hybridized with DNA strand 2 , leaving a single-stranded overhang (3). ssDNA-functionalized AuNPs (4) hybridize to the free DNA overhang to give superstructure 5. DNA strand 6 passivates all non-hybridized DNA strands on the AuNPs (7). Careful heating releases AuNPs with a single DNA overhang strand (8) which can be hybridized to ssDNA-saturated AuNP 9 to give planet-satellite structure 10 . b) DNA pairing sequences of various lengths between the $\mathrm{SiO}_{2} \mathrm{NP}$ and the AuNP. c) TEM image of a planet-satellite AuNP structures. Adapted from ref. [158].
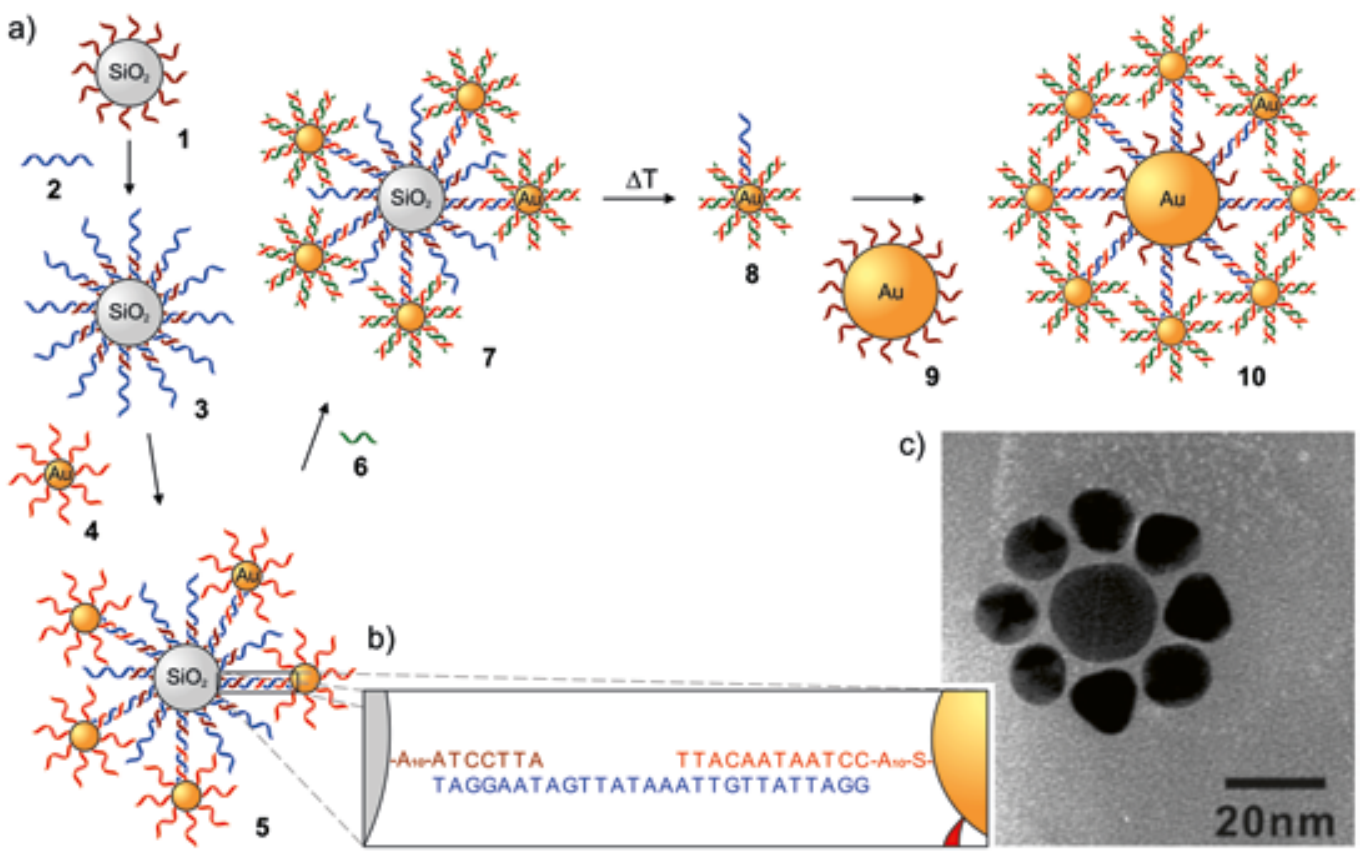

c)

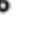

)

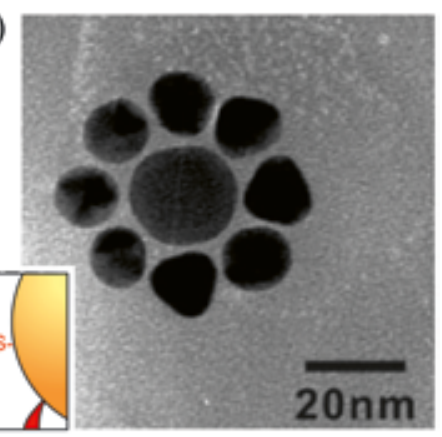


nanoparticle was decorated by iron terpyridine complexes exposing an amine, which were engaged in an amide formation with carboxy-functionalized AuNPs. Subsequent extraction of the iron ion gave AuNPs functionalized with a single terpyridine subunit. The monofunctionality of the AuNPs was corroborated by forming dumbbell-type dimers resulting from the addition of iron ions forming the homoleptic iron complex. ${ }^{[174]}$

\subsubsection{Janus Nanoparticles}

'Janus' particles are micro- and nanoparticles with two different surface compositions, named after the two-faced ancient Roman god. ${ }^{[175]}$ Although efforts of asymmetrical functionalization of AuNPs with few functional groups by partial surface-masking approaches have been reported, ${ }^{[176-178]}$ only very few publications on reliable monofunctionalization exist in this field. Li et al. proposed the fabrication of monfunctionalized AuNPs by a combination of Janus-type surface modification and exploiting the challenging sterics of bulky ligands. ${ }^{[179]}$ In their approach, AuNPs were stabilized with phosphine ligands, giving the AuNPs a net negative charge which allowed them to bind to positively charged silica beads. Ligand place-exchange with glutathione passivated the exposed surface while the silica-bound surface was still accessible for further ligand-exchange with clover-shaped thiolated DNA after HF-mediated release. Due to its bulkiness, the clover DNA strand hindered further functionalization of the AuNPs as proven by hybridization with larger, DNA-functionalized AuNPs, giving core-satellite structures.

In a similar approach, citrate-stabilized AuNPs were ligandexchanged to a glass slide functionalized with 3-mercaptopropyl-trimethoxy-silane. The exposed surface of the AuNPs was ligand-exchanged with cysteamine which was then attached to Cytochrome C, yielding AuNPs functionalized with a single protein. The absorption spectrum of these structures showed distinct dips next to the typical plasmon band in comparison with their unfunctionalized counterparts. This sharpening of the plasmon absorption was attributed to plasmon resonance energy transfer and identified as a promising property towards activity monitoring of biomarker proteins or in vivo electron transfer events. ${ }^{[180]}$

\subsection{Ligand-exchange in Living Systems}

Based on the pioneering accounts on the immunological response of biological systems on colloids by Steabben in the early twentieth century, ${ }^{[181]}$ Huang and co-workers proposed in vivo ligand-exchange to obtain AuNPs carrying one single immunoglobulin $\mathrm{G}$ for the measurement of the flexibility of immunoglobulin via TEM images ${ }^{[182]}$ or the construction of a piezoelectric sensor chip..$^{[183]}$ In a later report, they fabricated a transistor where the source-drain contact was established by an immunoglobulin $\mathrm{G}$ to which AuNPs were attached at each end, giving a molecular transistor which was not only gate-voltage dependent, but also modulated by the wavelength of the incident light. ${ }^{[184]}$

\section{Conclusion}

In the present review, the variety of methods yielding AuNPs exposing a single functional group are summarized. The so-obtained AuNPs become addressable by wet chemical protocols and behave like massive molecules. The reported AuNPs can be coarsely categorized in two types: Type I AuNPs that are stabilized by a single ligand comprising only one functional moiety and Type II AuNPs that are stabilized by multiple ligands, whereof only one bears the additional functionality of interest. The examples show that, despite their size and mass, monofunctionalized AuNPs in solution behave molecule-like with respect to their chemical function, exhibiting plasmonic and electrochemical behavior and are powerful tags in TEM experiments. With the methods presented here, large, highly ordered plasmonic AuNP assemblies can be fabricated with good control at the single-particle level. The re- ported AuNP assemblies act as model systems giving access to a variety of physical features such as plasmon quenching, fluorescence amplification, plasmon lensing, heat transfer via inductive coupling, as well as Förster- and plasmon resonance energy transfer processes. Alternatively, AuNPs, with a properly tuned functionality, act as effective, site-selective labels for a plethora of biomolecules and as physical barriers in mechanically interlinked superstructures. While the diversity of applications and the level of control achieved are impressive, the challenging aspect of most approaches is the limited sample size. While this is not an issue for biological systems where the handled sample size is usually equally tiny, it limits more the application potential of the methods in material science. There is plenty of room for improvements as far as the strategies towards larger batches of monofunctionalized AuNPs are concerned.

\section{Acknowledgements}

Financial support by the Swiss National Science Foundation (Grant no. 200020_178808), M. M. acknowledges support by the 111 project (90002-18011002)

Received: March 1, 2021

[1] M. Faraday, Phil. Trans. R. Soc. Lond. 1857, 147, 145, https://doi.org/10.1098/rstl.1857.0011.

[2] G. Mie, Ann. Phys. https://doi.org//10.1002/andp.19083300302.

[3] G. Schmid, U. Simon, Chem. Commun. 2005, 697 https://doi.org/10.1039/B411696H.

[4] G. Yue, S. Su, N. Li, M. Shuai, X. Lai, D. Astruc, P. Zhao, Coord. Chem. Rev. 2016, 311, 75, https://doi.org/10.1016/j.ccr.2015.11.009.

[5] R. Wilson, Chem. Soc. Rev. 2008, 37, 2028, https://doi.org/10.1039/B712179M.

[6] P. Zhao, X. Feng, D. Huang, G. Yang, D. Astruc, Coord. Chem. Rev. 2015 287, 114, https://doi.org/10.1016/j.ccr.2015.01.002.

[7] C. Wang, D. Astruc, Chem. Soc. Rev. 2014, 43, 7188, https://doi.org/10.1039/C4CS00145A.

[8] L. Pasquato, P. Pengo, P. Scrimin, Supramol. Chem. 2005, 17, 163 , https://doi.org/10.1080/10610270412331328817.

[9] S. Link, M. A. El-Sayed, J. Phys. Chem. B 1999, 103, 4212 , https://doi.org/10.1021/jp984796o.

[10] H. Xu, M. Käll, Sens. Actuators B Chem. 2002, 87, 244 https://doi.org/10.1016/S0925-4005(02)00243-5.

[11] W. Rechberger, A. Hohenau, A. Leitner, J. R. Krenn, B. Lamprecht, F. R. Aussenegg, Opt. Commun. 2003, 220, 137, https://doi.org/10.1016/S0030-4018(03)01357-9.

[12] N. Zohar, L. Chuntonov, G. Haran, J. Photochem. Photobiol. C 2014, 21 26, https://doi.org/10.1016/j.jphotochemrev.2014.10.002.

[13] D. Safer, J. Struct. Biol. 1999, 127, 101, https://doi.org/10.1006/jsbi.1999.4110.

[14] J. F. Hainfeld, 'Colloidal Gold: Principles, Methods, and Applications', Elsevier, 2012

[15] Y. Wu, M. R. K. Ali, K. Chen, N. Fang, M. A. El-Sayed, Nano Today 2019, 24, 120, https://doi.org/10.1016/j.nantod.2018.12.006.

[16] R. A. Sperling, P. R. Gil, F. Zhang, M. Zanella, W. J. Parak, Chem. Soc. Rev. 2008, 37, 1896, https://doi.org/10.1039/B712170A.

[17] J. F. Hainfeld, R. D. Powell, J Histochem Cytochem. 2000, 48, 471, https://doi.org/10.1177/002215540004800404.

[18] T. A. Gschneidtner, Y. A. D. Fernandez, K. Moth-Poulsen, J. Mater. Chem. C 2013, 1, 7127, https://doi.org/10.1039/C3TC31483A.

[19] G. Schmid, Adv. Eng. Mater. 2001, 3, 737, https://doi.org/10.1002/15272648(200110)3:10<737::AID-ADEM737>3.0.CO;2-8.

[20] J. Liao, S. Blok, S. J. van der Molen, S. Diefenbach, A. W. Holleitner, C. Schönenberger, A. Vladyka, M. Calame, Chem. Soc. Rev. 2015, 44, 999, https://doi.org/10.1039/C4CS00225C.

[21] J. Wang, J. Li, J. Li, F. Liu, Y. Gu, J. Fan, B. Dong, C. Wang, L. Qiu, L. Gao, S. Seong Lee, P. Jiang, Curr. Org. Chem. 2016, 20, 1786, https://doi.org/10.2174/1385272820666151105193200.

[22] H.-H. Wang, C.-H. Su, Y.-J. Wu, C.-A. J. Lin, C.-H. Lee, J.-L. Shen, W.-H. Chan, W. H. Chang, H.-I. Yeh, Int. J. Gerontol. 2012, 6, 1, https://doi.org/10.1016/j.ijge.2011.09.015.

[23] W. Baschong, N. G. Wrigley, J. Elec. Microsc. Tech. 1990, 14, 313, https://doi.org/10.1002/jemt.1060140405. 
[24] T. Carter, P. Mulholland, K. Chester, Immunotherapy 2016, 8, 941, https://doi.org/10.2217/imt.16.11.

[25] P. Kesharwani, H. Choudhury, J. G. Meher, M. Pandey, B. Gorain, Prog. Mater. Sci. 2019, 103, 484, https://doi.org/10.1016/j.pmatsci.2019.03.003.

[26] P. Zhao, N. Li, D. Astruc, Coord. Chem. Rev. 2013, 257, 638, https://doi.org/10.1016/j.ccr.2012.09.002

[27] T. Peterle, A. Leifert, J. Timper, A. Sologubenko, U. Simon, M. Mayor, Chem. Commun. 2008, 3438, https://doi.org/10.1039/B802460J.

[28] M. Lehmann, E. H. Peters, M. Mayor, Chem. Eur. J. 2016, 22, 2261, https://doi.org/10.1002/chem.201504575.

[29] E. H. Peters, M. Lehmann, M. Mayor, Part. Part. Syst. Charact. 2018, 35, 1800015, https://doi.org/10.1002/ppsc.201800015.

[30] R. Wilson, Chem. Commun. 2003, 108, https://doi.org/10.1039/B208170A

[31] R. Wilson, Y. Chen, J. Aveyard, Chem. Commun. 2004, 1156, https://doi.org/10.1039/B402786H.

[32] J. Aveyard, P. Nolan, R. Wilson, Anal. Chem. 2008, 80, 6001, https://doi.org/10.1021/ac800699k.

[33] Y. Chen, J. Aveyard, R. Wilson, Chem. Commun. 2004, 2804, https://doi.org/10.1039/B411181H.

[34] M. Mehrabi, R. Wilson, Small 2007, 3, 1491, https://doi.org/10.1002/smll.200700230.

[35] G. Yao, H. Pei, J. Li, Y. Zhao, D. Zhu, Y. Zhang, Y. Lin, Q. Huang, C. Fan, NPG Asia Mater 2015, 7, e159, https://doi.org/10.1038/am.2014.131.

[36] H. Xing, Y. Bai, Y. Bai, L. H. Tan, J. Tao, B. Pedretti, G. A. Vincil, Y. Lu, S. C. Zimmerman, J. Am. Chem. Soc. 2017, 139, 3623, https://doi.org/10.1021/jacs.7b00065

[37] Y. Bai, H. Xing, Y. Bai, L. H. Tan, K. Hwang, J. Li, Y. Lu, S. C. Zimmerman, Chem. Sci. 2020, 11, 1564, https://doi.org/10.1039/C9SC05656D.

[38] C. Krüger, S. Agarwal, A. Greiner, J. Am. Chem. Soc. 2008, 130, 2710, https://doi.org/10.1021/ja0763495.

[39] M. Brust, M. Walker, D. Bethell, D. J. Schiffrin, R. Whyman, J. Chem. Soc., Chem. Commun. 1994, 801, https://doi.org/10.1039/C39940000801.

[40] S. Bokern, K. Gries, H.-H. Görtz, V. Warzelhan, S. Agarwal, A. Greiner, Adv. Funct. Mater. 2011, 21, 3753, https://doi.org/10.1002/adfm.201100590.

[41] K. Gries, M. El Helou, G. Witte, S. Agarwal, A. Greiner, Polymer 2012, 53, 1632, https://doi.org/10.1016/j.polymer.2012.02.008.

[42] Z. Fan, X. Chen, M. Köhn Serrano, H. Schmalz, S. Rosenfeldt, S. Förster, S. Agarwal, A. Greiner, Angew. Chem. Int. Ed. 2015, 54, 14539, https://doi.org/10.1002/anie.201506415.

[43] Z. Fan, M. K. Serrano, A. Schaper, S. Agarwal, A. Greiner, Adv. Mater. 2015, 27, 3888, https://doi.org/10.1002/adma.201501306.

[44] S. R. Barman, A. Nain, S. Jain, N. Punjabi, S. Mukherji, J. Satija, J. Mater. Chem. B 2018, 6, 2368, https://doi.org/10.1039/C7TB03344C

[45] A. K. Ilunga, R. Meijboom, Catal. Lett. 2019, 149, 84 https://doi.org/10.1007/s10562-018-2584-0.

[46] B. I. Kharisov, H. V. R. Dias, O. V. Kharissova, A. Vázquez, J. Nanopart. Res. 2014, 16, 2665, https://doi.org/10.1007/s11051-014-2665-y.

[47] X. Li, K. Kono, Polym. Int. 2018, 67, 840, https://doi.org/10.1002/ pi.5583.

[48] W. M. Pankau, S. Mönninghoff, G. von Kiedrowski, Angew. Chem. Int. Ed. 2006, 45, 1889, https://doi.org/10.1002/anie.200502370.

[49] T. Peterle, P. Ringler, M. Mayor, Adv. Funct. Mater. 2009, 19, 3497, https://doi.org/10.1002/adfm.200901410.

[50] J. P. Hermes, F. Sander, T. Peterle, C. Cioffi, P. Ringler, T. Pfohl, M. Mayor, Small 2011, 7, 920, https://doi.org/10.1002/smll.201002101.

[51] J. P. Hermes, F. Sander, T. Peterle, R. Urbani, T. Pfohl, D. Thompson, M. Mayor, Chem. Eur. J. 2011, 17, 13473, https://doi.org/10.1002/chem.201101837.

[52] J. P. Hermes, F. Sander, U. Fluch, T. Peterle, D. Thompson, R. Urbani, T. Pfohl, M. Mayor, J. Am. Chem. Soc. 2012, 134, 14674, https://doi.org/10.1021/ja306253t.

[53] F. Sander, U. Fluch, J. P. Hermes, M. Mayor, Small 2014, 10, 349, https://doi.org/10.1002/smll.201300839.

[54] E. H. Peters, M. Mayor, Eur. J. Inorg. Chem. 2020, 2020, 2325, https://doi.org/10.1002/ejic.202000273.

[55] S. H. Kashani, A. Landarani-Isfahani, M. Moghadam, S. Tangestaninejad, V. Mirkhani, I. Mohammadpoor-Baltork, Appl. Organomet. Chem. 2018, 32, e4440, https://doi.org/10.1002/aoc.4440.

[56] X. Liu, Q. Ling, L. Zhao, G. Qiu, Y. Wang, L. Song, Y. Zhang, J. Ruiz, D. Astruc, H. Gu, Macromol. Rapid. Commun. 2017, 38, 1700448, https://doi.org/10.1002/marc.201700448.

[57] X. Liu, S. Mu, Y. Long, G. Qiu, Q. Ling, H. Gu, W. Lin, Catal. Lett. 2019, 149, 544, https://doi.org/10.1007/s10562-019-02662-5.

[58] F. Liu, X. Liu, D. Astruc, H. Gu, J. Colloid. Interface. Sci. 2019, 533, 161, https://doi.org/10.1016/j.jcis.2018.08.062.

[59] S.-F. Lee, Q. Wang, D. K.-L. Chan, P.-L. Cheung, K.-W. Wong, J. C. Yu, B. S. Ong, K. C.-F. Leung, New J. Chem. 2014, 38, 3362, https://doi.org/10.1039/C4NJ00318G.
[60] K. C.-F. Leung, X.-B. Li, X. Li, S.-F. Lee, J. C. Yu, P. M. Mendes, K. E. Hermann, M. A. V. Hove, Mater. Chem. Front. 2019, 3, 1555 , https://doi.org/10.1039/C9QM00132H

[61] L. Chen, W. Cao, N. Grishkewich, R. M. Berry, K. C. Tam, J. Colloid. Interface. Sci. 2015, 450, 101, https://doi.org/10.1016/j.jcis.2015.03.002.

[62] L. Chen, W. Cao, P. J. Quinlan, R. M. Berry, K. C. Tam, ACS Sustainable Chem. Eng. 2015, 3, 978, https://doi.org/10.1021/ acssuschemeng.5b00110.

[63] Md. A. Rahman, H.-B. Noh, Yoon-Bo Shim, Anal. Chem. 2008, 80, 8020, https://doi.org/10.1021/ac801033s.

[64] J. Turkevich, P. C. Stevenson, J. Hillier, Discuss. Faraday Soc. 1951, 11, 55, https://doi.org/10.1039/DF9511100055.

[65] F. Griffin, D. Fitzmaurice, Langmuir 2007, 23, 10262, https://doi.org/10.1021/la061261a.

[66] M. Brust, R. Etchenique, E. J. Calvo, G. J. Gordillo, Chem. Commun. 1996, 1949, https://doi.org/10.1039/CC9960001949.

[67] B. Nikoobakht, M. A. El-Sayed, Langmuir 2001, 17, 6368, https://doi.org/10.1021/la010530o.

[68] F. Cariati, L. Naldini, Inorganica Chim. Acta 1971, 5, 172, https://doi.org/10.1016/S0020-1693(00)95906-1.

[69] G. Schmid, R. Pfeil, R. Boese, F. Bandermann, S. Meyer, G. H M. Calis, J. W. A. van der Velden, Chem. Ber. 1981, 114, 3634, https://doi.org/10.1002/cber.19811141116.

[70] M. J. Hostetler, A. C. Templeton, R. W. Murray, Langmuir 1999, 15 3782, https://doi.org/10.1021/la981598f.

[71] A. W. Shaffer, J. G. Worden, Q. Huo, Langmuir 2004, 20, 8343, https://doi.org/10.1021/la049308k.

[72] F. A. Vollenbroek, J. P. Van den Berg, J. W. A. Van der Velden, J. J. Bour, Inorg. Chem. 1980, 19, 2685, https://doi.org/10.1021/ic50211a041.

[73] J. E. Reardon, P. A. Frey, Biochemistry 1984, 23, 3849, https://doi.org/10.1021/bi00312a009.

[74] H. Yang, J. E. Reardon, P. A. Frey, Biochemistry 1984, 23, 3857, https://doi.org/10.1021/bi00312a010.

[75] D. Safer, L. Bolinger, J. S. Leigh, J. Inorg. Biochem. 1986, 26, 77, https://doi.org/10.1016/0162-0134(86)80001-0.

[76] D. Safer, J. F. Hainfeld, J. S. Wall, Biophy. J. 1985, 47, 128a, https://doi.org/10.1016/S0006-3495(85)83902-3.

[77] W. Jahn, Z. Naturforsch. B 1989, 44b, 1313 , https://doi.org/10.1515/znb-1989-1027

[78] J. Crum, K. J. Gruys, T. G. Frey, Biochemistry 1994, 33, 13719 , https://doi.org/10.1021/bi00250a024

[79] J. F. Hainfeld, Science 1987, 236, 450, https://doi.org/10.1126/science.3563522.

[80] J. F. Hainfeld, M. Sprinzl, V. Mandiyan, S. J. Tumminia, M. Boublik, J. Struct. Biol. 1991, 107, 1, https://doi.org/10.1016/1047-8477(91)90024-Q.

[81] A. Zlotnick, N. Cheng, S. J. Stahl, J. F. Conway, A. C. Steven, P. T. Wingfield, PNAS 1997, 94, 9556 https://doi.org/10.1073/pnas.94.18.9556.

[82] B. Blechschmidt, W. Jahn, J. F. Hainfeld, M. Sprinzl, M. Boublik, J. Struct. Biol. 1993, 110, 84, https://doi.org/10.1006/jsbi.1993.1007.

[83] E. Skripkin, G. Yusupova, M. Yusupov, P. Kessler, C. Ehresmann, B. Ehresmann, Bioconjugate Chem. 1993, 4, 549, https://doi.org/10.1021/bc00024a019.

[84] B. Blechschmidt, V. Shirokov, M. Sprinzl, Eur. J. Biochem. 1994, 219, 65, https://doi.org/10.1111/j.1432-1033.1994.tb19915.x.

[85] J. F. Hainfeld, F. R. Furuya, J. Histochem. Cytochem. 1992, 40, 177, https://doi.org/10.1177/40.2.1552162.

[86] M. R. Narouz, K. M. Osten, P. J. Unsworth, R. W. Y. Man, K. Salorinne, S. Takano, R. Tomihara, S. Kaappa, S. Malola, C.-T. Dinh, J. D. Padmos, K. Ayoo, P. J. Garrett, M. Nambo, J. H. Horton, E. H. Sargent, H. Häkkinen, T. Tsukuda, C. M. Crudden, Nat. Chem. 2019, 11, 419, https://doi.org/10.1038/s41557-019-0246-5.

[87] NANOPROBES: Gold nanoparticles and Nanogold for immunolabeling, EM, LM, fluorescence microscopy, and micro-CT x-ray contrast agents, http://www.nanoprobes.com/, accessed November 14, 2019.

[88] J. F. Hainfeld, R. D. Leone, F. R. Furuya, R. D. Powell, US Patent $5,521,289, \mathbf{1 9 9 6}$

[89] A. P. Alivisatos, K. P. Johnsson, X. Peng, T. E. Wilson, C. J. Loweth, M. P. Bruchez, P. G. Schultz, Nature 1996, 382, 609 , https://doi.org/10.1038/382609a0.

[90] C.M. Niemeyer, W. Bürger, J.Peplies, Angew. Chem. Int. Ed. 1998, 37, 2265 https://doi.org/10.1002/(SICI)1521-3773(19980904)37:16<2265::AIDANIE2265>3.0.CO;2-F.

[91] K. Hamad-Schifferli, J. J. Schwartz, A. T. Santos, S. Zhang, J. M. Jacobson, Nature 2002, 415, 152, https://doi.org/10.1038/415152a

[92] K. Hamad-Schifferli, J. J. Schwartz, A. T. Santos, S. Zhang, J. M. Jacobson, Mat. Res. Soc. Symp. Proc. 2001, 676, Y8.43.1, https://doi.org/10.1557/PROC-676-Y8.43.

[93] F. Patolsky, Y. Weizmann, O. Lioubashevski, I. Willner, Angew. Chem. Int. Ed. 2002, 41, 2323, https://doi.org/10.1002/15213773(20020703)41:13<2323::AID-ANIE2323>3.0.CO;2-H. 
[94] Y. Xiao, F. Patolsky, E. Katz, J. F. Hainfeld, I. Willner, Science 2003, 299, 1877, https://doi.org/10.1126/science.1080664

[95] T. Pons, I. L. Medintz, K. E. Sapsford, S. Higashiya, A. F. Grimes, D. S. English, H. Mattoussi, Nano Lett. 2007, 7, 3157 , https://doi.org/10.1021/n1071729+.

[96] Z. Wang, R. Lévy, D. G. Fernig, M. Brust, Bioconjugate Chem. 2005, 16, 497, https://doi.org/10.1021/bc050047f

[97] R. Lévy, Z. Wang, L. Duchesne, R. C. Doty, A. I. Cooper, M. Brust, D. G. Fernig, ChemBioChem 2006, 7, 592, https://doi.org/10.1002/cbic.200500457.

[98] R. Lévy, ChemBioChem 2006, 7, 1141 , https://doi.org/10.1002/cbic.200600129.

[99] L. Duchesne, D. Gentili, M. Comes-Franchini, D. G. Fernig, Langmuir 2008 24, 13572, https://doi.org/10.1021/la802876u.

[100] L. Duchesne, V. Octeau, R. N. Bearon, A. Beckett, I. A. Prior, B. Lounis, D. G. Fernig, PLOS Biology 2012, 10, e1001361, https://doi.org/10.1371/journal.pbio.1001361.

[101] C. Leduc, S. Si, J. Gautier, M. Soto-Ribeiro, B. Wehrle-Haller, A. Gautreau, G. Giannone, L. Cognet, B. Lounis, Nano Lett. 2013, 13, 1489 , https://doi.org/10.1021/nl304561g.

[102] D. J. Nieves, N. S. Azmi, R. Xu, R. Lévy, E. A. Yates, D. G. Fernig, Chem. Commun. 2014, 50, 13157, https://doi.org/10.1039/C4CC05909C.

[103] D. Paramelle, D. Nieves, B. Brun, R. S. Kraut, D. G. Fernig, Adv. Healthc. Mater. 2015, 4, 911, https://doi.org/10.1002/adhm.201400730.

[104] L. Duchesne, G. Wells, D. G. Fernig, S. A. Harris, R. Lévy, ChemBioChem 2008, 9, 2127, https://doi.org/10.1002/cbic.200800326.

[105] Y. Jun, S. Sheikholeslami, D. R. Hostetter, C. Tajon, C. S. Craik, A. P. Alivisatos, PNAS 2009, 106, 17735, https://doi.org/10.1073/pnas.0907367106.

[106] L. C. Brousseau III, J. P. Novak, S. M. Marinakos, D. L. Feldheim, Adv. Mater. 1999, 11, 447, https://doi.org/10.1002/(SICI)15214095(199904)11:6<447::AID-ADMA447>3.0.CO;2-I.

[107] C. A. Otter, P. J. Patty, M. A. K. Williams, M. R. Waterland, S. G. Telfer, Nanoscale 2011, 3, 941, https://doi.org/10.1039/C0NR00801J.

[108] C. J. Loweth, W. B. Caldwell, X. Peng, A. P. Alivisatos, P. G. Schultz, Angew. Chem. Int. Ed. 1999, 38, 1808, https://doi.org/10.1002/(SICI)15213773(19990614)38:12<1808::AID-ANIE1808>3.0.CO;2-C.

[109] S. A. Claridge, H. W. Liang, S. R. Basu, J. M. J. Fréchet, A. P. Alivisatos, Nano Lett. 2008, 8, 1202, https://doi.org/10.1021/n10802032.

[110] T. Pellegrino, R. A. Sperling, A. P. Alivisatos, W. J. Parak, J. Biomed. Biotechnol. 2007, 26796, https://doi.org/10.1155/2007/26796.

[111] D. Zanchet, C. M. Micheel, W. J. Parak, D. Gerion, A. P. Alivisatos, Nano Lett. 2001, 1, 32, https://doi.org/10.1021/nl005508e.

[112] D. Zanchet, C. M. Micheel, W. J. Parak, D. Gerion, S. C. Williams, A. P. Alivisatos, J. Phys. Chem. B 2002, 106, 11758 , https://doi.org/10.1021/jp026144c.

[113] Y. Akiyama, H. Shikagawa, N. Kanayama, T. Takarada, M. Maeda, Small 2015, 11, 3153, https://doi.org/10.1002/smll.201500045.

[114] L. Lermusiaux, A. Sereda, B. Portier, E. Larquet, S. Bidault, ACS Nano 2012, 6, 10992, https://doi.org/10.1021/nn304599d.

[115] F. A. Aldaye, H. F. Sleiman, J. Am. Chem. Soc. 2007, 129, 4130, https://doi.org/10.1021/ja070017i.

[116] S. A. Claridge, S. L. Goh, J. M. J. Fréchet, S. C. Williams, C. M. Micheel, A. P. Alivisatos, Chem. Mater. 2005, 17, 1628, https://doi.org/10.1021/cm0484089.

[117] Z. Deng, Y. Tian, S.-H. Lee, A. E. Ribbe, C. Mao, Angew. Chem. Int. Ed. 2005, 44, 3582, https://doi.org/10.1002/anie.200463096.

[118] A. J. Mastroianni, S. A. Claridge, A. P. Alivisatos, J. Am. Chem. Soc. 2009, 131, 8455, https://doi.org/10.1021/ja808570g

[119] H. Gu, J. Chao, S.-J. Xiao, N. C. Seeman, Nature 2010, 465, 202 https://doi.org/10.1038/nature09026.

[120] J. Zheng, P. E. Constantinou, C. Micheel, A. P. Alivisatos, R. A. Kiehl, N. C. Seeman, Nano Lett. 2006, 6, 1502, https://doi.org/10.1021/nl060994c.

[121] J. Sharma, R. Chhabra, Y. Liu, Y. Ke, H. Yan, Angew. Chem. Int. Ed. 2006, 45 730, https://doi.org/10.1002/anie.200503208.

[122] J. Sharma, R. Chhabra, C. S. Andersen, K. V. Gothelf, H. Yan, Y. Liu, J. Am. Chem. Soc. 2008, 130, 7820, https://doi.org/10.1021/ja802853r.

[123] L. Lermusiaux, V. Maillard, S. Bidault, ACS Nano 2015, 9, 978, https://doi.org/10.1021/nn506947g.

[124] M. P. Busson, B. Rolly, B. Stout, N. Bonod, E. Larquet, A. Polman, S. Bidault, Nano Lett. 2011, 11, 5060, https://doi.org/10.1021/nl2032052.

[125] L. Lermusiaux, S. Bidault, Langmuir 2018, 34, 14946, https://doi.org/10.1021/acs.langmuir.8b00133.

[126] S. Bidault, A. Devilez, P. Ghenuche, B. Stout, N. Bonod, J. Wenger, ACS Photonics 2016, 3, 895, https://doi.org/10.1021/acsphotonics.6b00148.

[127] S. Bidault, F. J. García de Abajo, A. Polman, J. Am. Chem. Soc. 2008, 130, 2750, https://doi.org/10.1021/ja711074n.

[128] A. Cecconello, C.-H. Lu, J. Elbaz, I. Willner, Nano Lett. 2013, 13, 6275, https://doi.org/10.1021/n1403884w.

[129] H. Mertens, A. F. Koenderink, A. Polman, Phys. Rev. B 2007, 76, 115123, https://doi.org/10.1103/PhysRevB.76.115123.

[130] E. Fort, S. Grésillon, J. Phys. D: Appl. Phys. 2007, 41, 013001, https://doi.org/10.1088/0022-3727/41/1/013001.

[131] J. Elbaz, A. Cecconello, Z. Fan, A. O. Govorov, I. Willner, Nat. Commun. 2013, 4, 2000, https://doi.org/10.1038/ncomms3000.
[132] J. List, E. Falgenhauer, E. Kopperger, G. Pardatscher, F. C. Simmel, Nat. Commun. 2016, 7, https://doi.org/10.1038/ncomms 12414.

[133] C. Sönnichsen, B. M. Reinhard, J. Liphardt, A. P. Alivisatos, Nat. Biotechnol. 2005, 23, 741, https://doi.org/10.1038/nbt1100.

[134] B. M. Reinhard, S. Sheikholeslami, A. Mastroianni, A. P. Alivisatos, J. Liphardt, PNAS 2007, 104, 2667, https://doi.org/10.1073/pnas.0607826104.

[135] C. Zhang, J. Ma, J. Yang, S. Liu, J. Xu, Anal. Chem. 2013, 85, 11973 , https://doi.org/10.1021/ac402908y.

[136] C. Zhang, R. Wu, Y. Li, Q. Zhang, J. Yang, Langmuir 2017, 33, 12285 , https://doi.org/10.1021/acs.langmuir.7b02620.

[137] R. A. Sperling, T. Pellegrino, J. K. Li, W. H. Chang, W. J. Parak, $A d v$. Funct. Mater. 2006, 16, 943, https://doi.org/10.1002/adfm.200500589.

[138] J. Lipka, M. Semmler-Behnke, R. A. Sperling, A. Wenk, S. Takenaka, C. Schleh, T. Kissel, W. J. Parak, W. G. Kreyling, Biomaterials 2010, 31, 6574, https://doi.org/10.1016/j.biomaterials.2010.05.009.

[139] J.-Y. Kim, H.-B. Kim, D.-J. Jang, Electrophoresis 2013, 34, 911, https://doi.org/10.1002/elps.201200492.

[140] L. Ma, F. Li, T. Fang, J. Zhang, Q. Wang, ACS Appl. Mater. Interfaces 2015, 7, 11024, https://doi.org/10.1021/acsami.5b02823.

[141] T. Lahtinen, E. Hulkko, K. Sokołowska, T.-R. Tero, V. Saarnio, J. Lindgren, M. Pettersson, H. Häkkinen, L. Lehtovaara, Nanoscale 2016, 8, 18665, https://doi.org/10.1039/C6NR05267C.

[142] K. Sokołowska, E. Hulkko, L. Lehtovaara, T. Lahtinen, J. Phys. Chem. C 2018, 122, 12524, https://doi.org/10.1021/acs.jpcc.8b02988.

[143] K. Sokołowska, Z. Luan, E. Hulkko, C. Rameshan, N. Barrabés, V. A. Apkarian, T. Lahtinen, J. Phys. Chem. Lett. 2020, 11, 796, https://doi.org/10.1021/acs.jpclett.9b03496.

[144] W. Chen, A. Bian, A. Agarwal, L. Liu, H. Shen, L. Wang, C. Xu, N. A Kotov, Nano Lett. 2009, 9, 2153, https://doi.org/10.1021/n1900726s.

[145] Y. Zhao, L. Xu, H. Kuang, L. Wang, C. Xu, J. Mater. Chem. 2012, 22 5574, https://doi.org/10.1039/C2JM15800K

[146] W. Yan, W. Ma, H. Kuang, L. Liu, L. Wang, L. Xu, C. Xu, J. Phys. Chem C 2013, 117, 17757, https://doi.org/10.1021/jp405925q.

[147] W. Yan, L. Xu, C. Xu, W. Ma, H. Kuang, L. Wang, N. A. Kotov, J. Am. Chem. Soc. 2012, 134, 15114, https://doi.org/10.1021/ja3066336.

[148] Y. Zhao, L. Xu, L. M. Liz-Marzán, H. Kuang, W. Ma, A. Asenjo-García, F. J. García de Abajo, N. A. Kotov, L. Wang, C. Xu, J. Phys. Chem. Lett. 2013, 4, 641, https://doi.org/10.1021/jz400045s.

[149] S. D. Jhaveri, E. E. Foos, D. A. Lowy, E. L. Chang, A. W. Snow, M. G. Ancona, Nano Lett. 2004, 4, 737, https://doi.org/10.1021/n10499591.

[150] X. Zhang, L. Liu, J. Tian, J. Zhang, H. Zhao, Chem. Commun. 2008, 6549, https://doi.org/10.1039/B815778B.

[151] J. Tian, F. Zheng, Q. Duan, H. Zhao, J. Mater. Chem. 2011, 21, 16928 , https://doi.org/10.1039/C1JM11384D.

[152] X. Zhang, Y. Yang, J. Tian, H. Zhao, Chem. Commun. 2009, 3807, https://doi.org/10.1039/B906967D.

[153] J. Tian, L. Yuan, M. Zhang, F. Zheng, Q. Xiong, H. Zhao, Langmuir 2012, 28, 9365, https://doi.org/10.1021/la301453n.

[154] J. Tian, G. Liu, C. Guan, H. Zhao, Polym. Chem. 2013, 4, 1913, https:// doi.org/10.1039/C2PY20967E.

[155] T.-J. Yim, Y. Wang, X. Zhang, Nanotechnology 2008, 19, 435605, https://doi.org/10.1088/0957-4484/19/43/435605.

[156] T. Dadosh, Y. Gordin, R. Krahne, I. Khivrich, D. Mahalu, V. Frydman, J. Sperling, A. Yacoby, I. Bar-Joseph, Nature 2005, 436, 677, https://doi.org/10.1038/nature03898.

[157] A. S. D. S. Indrasekara, B. J. Paladini, D. J. Naczynski, V. Starovoytov, P. V. Moghe, L. Fabris, Adv. Healthc. Mater. 2013, 2, 1370 https://doi org/10.1002/adhm.201200370.

[158] F. Huo, A. K. R. Lytton-Jean, C. A. Mirkin, Adv. Mater. 2006, 18, 2304, https://doi.org/10.1002/adma.200601178.

[159] A. Ulfkjær, F. W. Nielsen, H. Al-Kerdi, T. Ruß, Z. K. Nielsen, J. Ulstrup, L. Sun, K. Moth-Poulsen, J. Zhang, M. Pittelkow, Nanoscale 2018, 10, 9133, https://doi.org/10.1039/C8NR01622D

[160] J. G. Worden, A. W. Shaffer, Q. Huo, Chem. Commun. 2004, 518 , https://doi.org/10.1039/B312819A.

[161] J. G. Worden, Q. Dai, A. W. Shaffer, Q. Huo, Chem. Mater. 2004, 16 3746, https://doi.org/10.1021/cm048907+

[162] Z. Zhang, F. Rong, Y. Xie, Y. Wang, H. Yang, D. Fu, J. Nanosci. Nanotech 2011, 11, 2163, https://doi.org/10.1166/jnn.2011.3132.

[163] Q. Dai, J. G. Worden, J. Trullinger, Q. Huo, J. Am. Chem. Soc. 2005, 127, 8008, https://doi.org/10.1021/ja042610v.

[164] J. G. Worden, Q. Dai, Q. Huo, Chem. Commun. 2006, 1536, https://doi.org/10.1039/B600641H.

[165] W. Sun, Q. Dai, J. G. Worden, Q. Huo, J. Phys. Chem. B 2005, 109, 20854 https://doi.org/10.1021/jp055109d.

[166] G. Ramakrishna, Q. Dai, J. Zou, Q. Huo, T. Goodson, J. Am. Chem. Soc 2007, 129, 1848, https://doi.org/10.1021/ja067123p.

[167] O. Abed, A. Vaskevich, R. Arad-Yellin, A. Shanzer, I. Rubinstein, Chem. Eur. J. 2005, 11, 2836, https://doi.org/10.1002/chem.200401171.

[168] K.-M. Sung, D. W. Mosley, B. R. Peelle, S. Zhang, J. M. Jacobson, J. Am. Chem. Soc. 2004, 126, 5064, https://doi.org/10.1021/ja049578p. 
[169] C.-P. Chak, S. Xuan, P. M. Mendes, J. C. Yu, C. H. K. Cheng, K. C.-F. Leung, ACS Nano 2009, 3, 2129, https://doi.org/10.1021/nn9005895.

[170] C.-P. Chak, J. M. Y. Lai, K. W. Y. Sham, C. H. K. Cheng, K. C.-F. Leung, RSC Adv. 2011, 1, 1342, https://doi.org/10.1039/C1RA00304F.

[171] X. Liu, J. G. Worden, Q. Dai, J. Zou, J. Wang, Q. Huo, Small 2006, 2, 1126, https://doi.org/10.1002/smll.200600162.

[172] J. Zou, Q. Dai, J. Wang, X. Liu, Q. Huo, J. Nanosci. Nanotech. 2007, 7, 2382, https://doi.org/10.1166/jnn.2007.424.

[173] J.-H. Kim, J.-W. Kim, Langmuir 2008, 24, 5667, https://doi.org/10.1021/la800506g.

[174] M. R. Dewi, T. A. Gschneidtner, S. Elmas, M. Ranford, K. Moth-Poulsen, T. Nann, ACS Nano 2015, 9, 1434, https://doi.org/10.1021/nn5058408.

[175] C. Casagrande, M. Veyssié, C. R. Acad. Sci. Paris 1988, 306, 1423.

[176] B. Dong, B. Li, C. Y. Li, J. Mater. Chem. 2011, 21, 13155, https://doi.org/10.1039/C1JM12866C.

[177] B. Li, C. Y. Li, J. Am. Chem. Soc. 2007, 129, 12, https://doi.org/10.1021/ja0668318.

[178] V. Paraschiv, S. Zapotoczny, M. R. de Jong, G. J. Vancso, J. Huskens, D. N. Reinhoudt, Adv. Mater. 2002, 14, 722, https://doi.org/10.1002/15214095(20020517)14:10<722::AID-ADMA722>3.0.CO;2-T.

[179] Z. Li, E. Cheng, W. Huang, T. Zhang, Z. Yang, D. Liu, Z. Tang, J. Am. Chem. Soc. 2011, 133, 15284, https://doi.org/10.1021/ja205712a.
[180] G. L. Liu, Y.-T. Long, Y. Choi, T. Kang, L. P. Lee, Nature Methods 2007, 4 1015, https://doi.org/10.1038/nmeth1133.

[181] D. B. Steabben, Br. J. Exp. Pathol. 1925, 6, 1.

[182] G. S. Huang, Y.-S. Chen, H.-W. Yeh, Nano Lett. 2006, 6, 2467, https://doi.org/10.1021/n1061598x.

[183] G. S. Huang, Yu-Shiun Chen, Xin-Yau Lin, in '2007 7th IEEE Conference on Nanotechnology (IEEE NANO)', 2007, pp. 7, https://doi.org/10.1109/NANO.2007.4601129.

[184] Y.-S. Chen, M.-Y. Hong, G. S. Huang, Nat. Nanotechnol. 2012, 7, 197, https://doi.org/10.1038/nnano.2012.7.

\section{License and Terms}

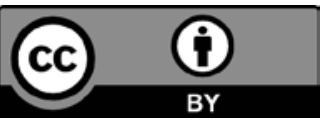

This is an Open Access article under the terms of the Creative Commons Attribution License CC BY 4.0. The material may not be used for commercial purposes.

The license is subject to the CHIMIA terms and conditions: (http:// chimia.ch/component/sppagebuilder/?view=page \&id=12).

The definitive version of this article is the electronic one that can be found at https://doi.org/10.2533/chimia.2021.414 